\title{
Noninvasive Electroencephalography Equipment for Assistive, Adaptive, and Rehabilitative Brain-Computer Interfaces: A Systematic Literature Review
}

\author{
Nuraini Jamil ${ }^{1}\left(\mathbb{D}\right.$, Abdelkader Nasreddine Belkacem $^{2, * \mathbb{D}}$, Sofia Ouhbi ${ }^{1}$ and $^{(}$Abderrahmane Lakas $^{2} \mathbb{D}$ \\ 1 Department of Computer Science and Software Engineering, College of Information Technology, \\ United Arab Emirates University, Al Ain P.O. Box 15551, United Arab Emirates; 201990167@uaeu.ac.ae (N.J.); \\ sofia.ouhbi@uaeu.ac.ae (S.O.) \\ 2 Department of Computer and Network Engineering, College of Information Technology, United Arab \\ Emirates University, Al Ain P.O. Box 15551, United Arab Emirates; alakas@uaeu.ac.ae \\ * Correspondence: belkacem@uaeu.ac.ae
}

\section{check for} updates

Citation: Jamil, N.; Belkacem, A.N.; Ouhbi, S.; Lakas, A. Noninvasive Electroencephalography Equipment for Assistive, Adaptive, and Rehabilitative Brain-Computer Interfaces: A Systematic Literature Review. Sensors 2021, 21, 4754. https://doi.org/10.3390/s21144754

Academic Editors: Miguel Ángel López Gordo and Christian A. Morillas Gutiérrez

Received: 6 June 2021

Accepted: 9 July 2021

Published: 12 July 2021

Publisher's Note: MDPI stays neutral with regard to jurisdictional claims in published maps and institutional affiliations.

Copyright: (c) 2021 by the authors. Licensee MDPI, Basel, Switzerland. This article is an open access article distributed under the terms and conditions of the Creative Commons Attribution (CC BY) license (https:/ / creativecommons.org/licenses/by/ $4.0 /)$.

\begin{abstract}
Humans interact with computers through various devices. Such interactions may not require any physical movement, thus aiding people with severe motor disabilities in communicating with external devices. The brain-computer interface (BCI) has turned into a field involving new elements for assistive and rehabilitative technologies. This systematic literature review (SLR) aims to help BCI investigator and investors to decide which devices to select or which studies to support based on the current market examination. This examination of noninvasive EEG devices is based on published BCI studies in different research areas. In this SLR, the research area of noninvasive BCIs using electroencephalography (EEG) was analyzed by examining the types of equipment used for assistive, adaptive, and rehabilitative BCIs. For this SLR, candidate studies were selected from the IEEE digital library, PubMed, Scopus, and ScienceDirect. The inclusion criteria (IC) were limited to studies focusing on applications and devices of the BCI technology. The data used herein were selected using IC and exclusion criteria to ensure quality assessment. The selected articles were divided into four main research areas: education, engineering, entertainment, and medicine. Overall, 238 papers were selected based on IC. Moreover, 28 companies were identified that developed wired and wireless equipment as means of $\mathrm{BCI}$ assistive technology. The findings of this review indicate that the implications of using BCIs for assistive, adaptive, and rehabilitative technologies are encouraging for people with severe motor disabilities and healthy people. With an increasing number of healthy people using BCIs, other research areas, such as the motivation of players when participating in games or the security of soldiers when observing certain areas, can be studied and collaborated using the BCI technology. However, such BCI systems must be simple (wearable), convenient (sensor fabrics and self-adjusting abilities), and inexpensive.
\end{abstract}

Keywords: adaptive technology; assistive technology; brain-computer interface; EEG equipment; rehabilitative technology

\section{Introduction}

Most people know someone or have heard of someone who suffers from paralysis. In most cases, people become paralyzed because of accidents or medical conditions that partially or entirely affect the way their muscles and nerves function. People with disabilities do not usually receive the support they need because caring for them can be very expensive. Brain-computer interface (BCI) technology is now implemented in the treatment of patients suffering from physical impairments [1-3]. This technology promises to significantly enhance the quality of life of such patients by considerably improving their autonomy and mobility. Moreover, the idea of interfacing brains with machines has long captured human imagination [2]. Paralyzed people with neurological diseases (e.g., locked-in syndrome, 
muscular dystrophy, amyotrophic lateral sclerosis, brainstem stroke, and spinal cord injury) experience difficulties, such as in walking, speaking, and writing, because they lose fine motor control or lack a complete control of their voluntary muscles. However, their thinking capabilities are usually the same as those of nondisabled individuals. Generally, such patients are conscious and their mental abilities are unimpaired.

Consequently, research in neurology focuses on monitoring brain activities and incorporating the resulting data into BCIs. For instance, brain data can be used to allow patients to control home appliances or the movement of a wheelchair in four directions [4,5], send a message [6], or write an e-mail [6,7]. While Fazel-Rezai et al. [8] discussed some other applications that use the BCI technology. The brain activities can be noninvasively recorded using sensors on the scalp or invasively recorded using terminals set on the brain surface or inside the cerebrum. The popularity of such technologies is increasing because they can support the daily activities of people suffering from severe motor disabilities $[9,10]$. Healthy people can also use BCIs with other applications, particularly in games such as Tetris [11] and Brain Invaders, using the P300 paradigm with the OpenViBE platform [12]. They can also be used in virtual environments (aircraft simulators) [13].

BCI applications mainly aim to help people with severe motor impairments in living their lives like ordinary people as much as possible. Several devices using BCIs have been developed to assist in human activities [14]. Furthermore, several studies have proposed ways for helping people with severe impairments, such as paralysis and brain strokes, to ensure communication using direct links between brains and devices $[4,15,16]$. A BCI device's main objective is to re-establish usable capacities of individuals with neuromuscular disorders. BCI procedures require the extraction of signal features from the cerebrum. Then, these features are analyzed and transformed into commands. An overview of a typical BCI system is illustrated in Figure 1.

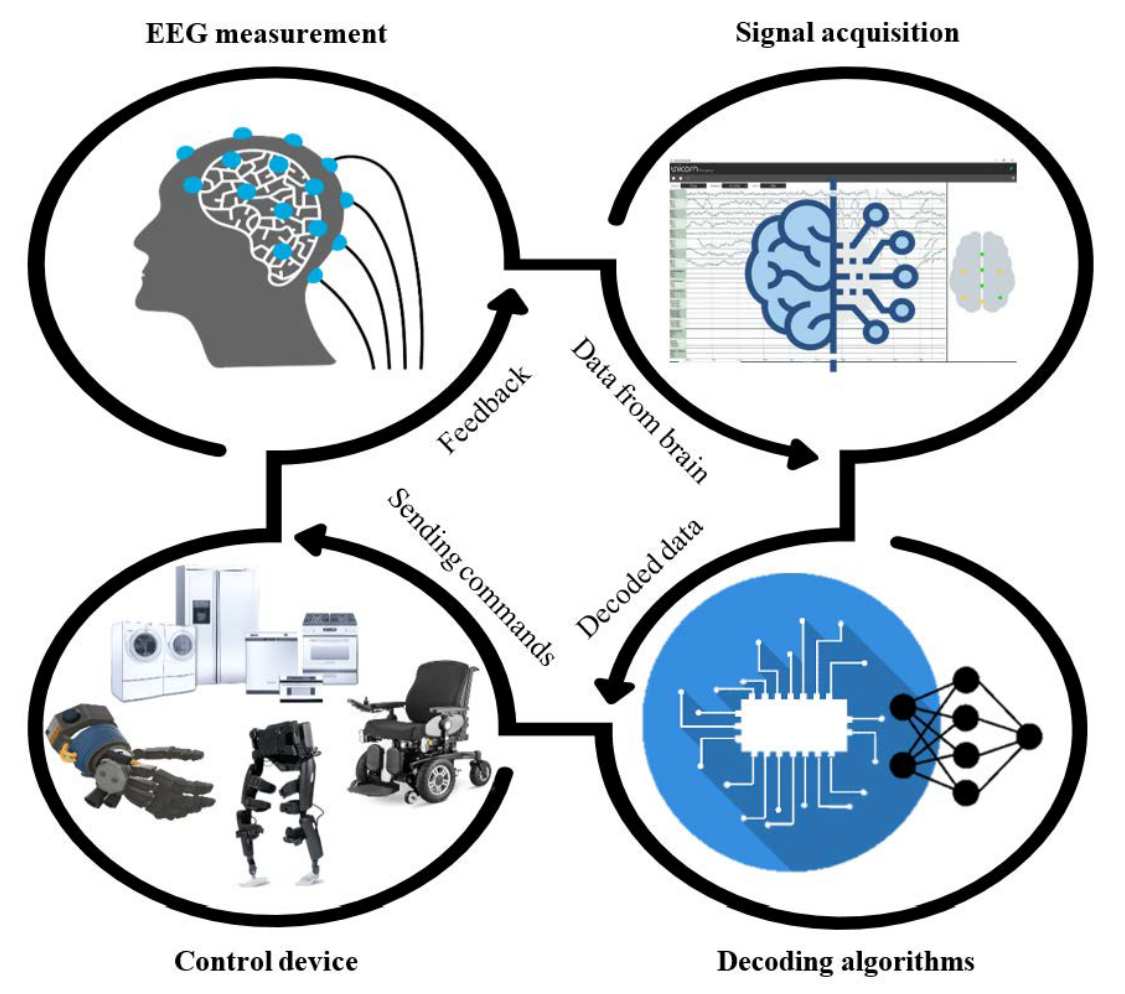

Figure 1. Brain-computer interface system.

The methods used to observe brain activities can be classified into noninvasive and invasive methods, and the contrast between these methods is based on the electrode placement. For invasive procedures, a patient must undergo neurosurgery, where an electrode is directly implemented into the brain using a single BCI unit or multiple units. 
The brain area can be monitored using the BCI unit [17]. Here, the signals produced are of high quality; however, the negative impact of this method is significant owing to the increase in the brain's scar tissue [18]. An example of the invasive method is electrocorticography $(\mathrm{ECoG})$, where brain activities are straightforwardly recorded from the brain surface [19].

The noninvasive method is less costly than the invasive method and causes minimal discomfort, and it is highly decisive [14]. For instance, an EEG tracks and records the brain wave patterns using electrodes placed on the scalp. Based on the acquired wave patterns, the signals are then dispatched to a computer. Figure 2 shows some commercial noninvasive EEG equipment.

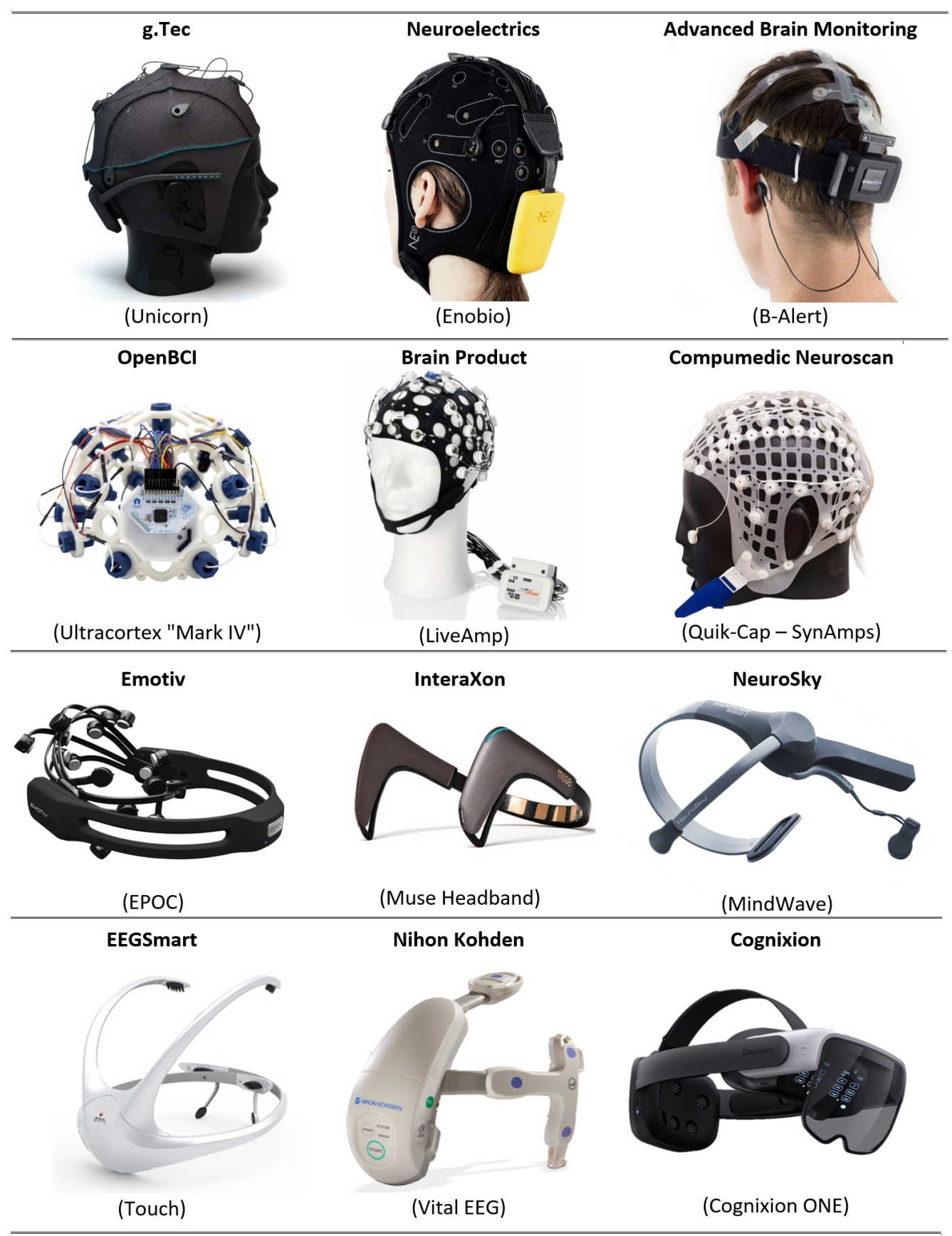

Figure 2. Examples of the commercial noninvasive EEG equipment based on the BCI technology. EEGSmart, Nihon Kohden, and Cognixion refer to the future noninvasive EEG designs. 
The EEG primary paradigm includes motor imagery (MI), P300, and steady-state visual evoked potential (SSVEP) [20], which are different in the way in which they capture signals. These three paradigms have different approaches and potentials. In P300, if the subject is passionately engaged in a task, the EEG wave occurs with a high positive peak after $300 \mathrm{~ms}$ of a stimulus in a human-event-related potential. Conversely, MI is concerned with the psychological process of a movement without muscle actuation [21].

Rehabilitation is one of the therapy and training methods to restore the motor and muscle damage. Examples are robot-aided therapy [22] or using imagery cues to transform activity practices into daily routines suitable for therapy. For instance, a patient only imagines the action, such as grasping a bottle. Then, the brain signal sends the command to the device to control the movement. Remsik et al. [23] proposed two methods of using $\mathrm{BCI}$ systems for people with impairments to regain motor control. The first method is to train patients to deliver additional motor brain signals, and the second one is to train patients to activate devices that improve the motor function. The EEG method is revealing the remarkable improvements and continuous changes, even though individuals with procured motor impairments regularly display damaged cortices or problems with motor connections. Ramos-Murguialday et al. [24] introduced the aftereffects of the randomized control of a preliminary of 16 patients with chronic stroke using a BCI for the hand and arm orthotic feedback.

Assistive technology enables people with physical impairments to communicate, participate in communities, play, and move like ordinary people using a piece of equipment. This technology can reduce the stress of caregivers in terms of thinking about people with disabilities $[25,26]$.

Adaptive technology refers to the enhanced versions of the existing tools that offer extra features and interaction opportunities to help people perform specific tasks [27], such as in education. Zhang [28] proved that students, particularly Chinese students, can better learn English using BCIs. Chiang et al. [29] measured the attention level of students and concluded that they can become more focused and learn better using BCIs.

To sum up, herein, a systematic literature review (SLR) is conducted to address the following research questions (RQs) as shown in Table 1.

Table 1. SLR research questions.

\begin{tabular}{lll}
\hline & Research Question & Rationale \\
\hline RQ1 & $\begin{array}{l}\text { What are the publication trends based } \\
\text { on EEG equipment? }\end{array}$ & $\begin{array}{l}\text { To identify the sector that collaborates } \\
\text { with BCI technology using the } \\
\text { EEG method }\end{array}$ \\
\hline RQ2 & $\begin{array}{l}\text { What are the most common types } \\
\text { (wired or wireless) of noninvasive } \\
\text { EEG-based BCI equipment that have } \\
\text { been used in brain studies? }\end{array}$ & $\begin{array}{l}\text { To discover whether the EEG } \\
\text { equipment mostly uses the wired or } \\
\text { wireless type based on a specific } \\
\text { research area }\end{array}$ \\
\hline
\end{tabular}

Therefore, the main aim of this review is to identify the related literature with BCI equipment that can support various research fields. Further, the existing brands and types of commercial EEG equipment used for assistive, adaptive, and rehabilitative BCI technologies are reviewed.

This SLR is structured as follows. First, a research methodology was used to retrieve all the related articles by using online search databases (IEEEXplore, Scopus, PubMed, and ScienceDirect). Then, the analysis results from systematic review are summarized based on the company and type of devices. Finally, a discussion was performed, conclusions were drawn based on the findings, and future research areas were proposed to enhance the impact of the result. 


\section{Methods}

\subsection{Search Strategy}

This SLR was investigated considering the rehabilitative, assistive, and adaptive technologies using the noninvasive $\mathrm{BCI}$ technology based on the preferred reporting items for systematic reviews meta-analyses (PRISMA) [30] (Figure 3). The following online electronic databases were used to search for relevant studies: PubMed, IEEE, Scopus, and ScienceDirect. The search string used in the search process was "(BCI OR "Brain-computer interface" OR BMI OR "brain-machine interface") AND (EEG OR electroencephalogram) AND (rehab* OR assist* OR adapt*)." This search string was used in the digital libraries to search for the title, keywords, and abstract of candidate publications. The search was finalized in early February 2021.

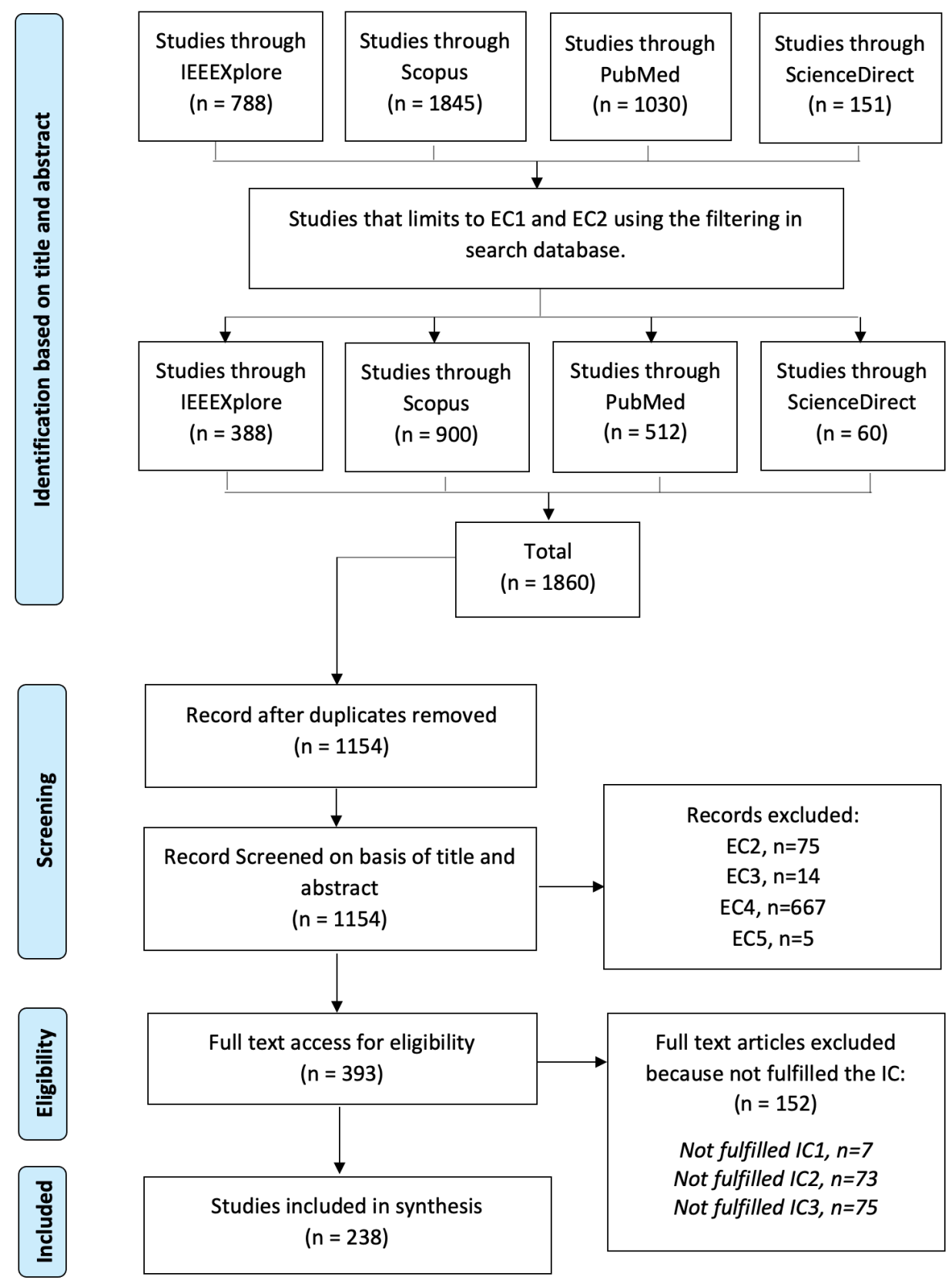

Figure 3. Flow process using the PRISMA method. 


\subsection{Inclusion and Exclusion Criteria}

The studies included in this SLR were selected based on the following inclusion criteria (IC): (IC1) studies in which EEG was used as a noninvasive BCI, (IC2) studies in which commercial brands and companies of EEG equipment were mentioned, and (IC3) studies focusing on devices and applications for rehabilitation, assistive, and adaptive environments in real life.

The exclusion criteria (EC) for this SLR are (EC1) publications published before 2016 and after 2020, (EC2) studies that are not prereview papers or survey/review papers and chapters, (EC3) non-English articles, (EC4) studies that did not focus on devices and focused more on the outcomes of algorithms, classifications, and brain areas, and (EC5) articles that cannot be retrieved as full articles.

\subsection{Data Extraction}

We extract the following characteristic:

1. Brand and company: The brand names of the EEG equipment and the company names that produce them.

2. Type of EEG equipment: The articles that use either wired or wireless equipment. Nowadays, many applications provide wireless equipment because of its low cost and physical mobility [31].

3. The sector of using EEG equipment: A broad area of applications that use BCIs as information sources [32].

\section{Results}

A considerable number of papers were analyzed, including those concerned with assistive, adaptive, and rehabilitative BCI technologies. This SLR retrieved 1860 articles; however, only 238 articles were included after screening using the aforementioned eligibility criteria. EC2 was employed again because some databases did not provide specific research type filters (Figure 3). Further, some reviews and survey papers are often identified as journal types.

\section{RQ1: What are the publication trends based on EEG equipment?}

Figure 4 shows the percentage proportion chart of the four main research areas identified in this SLR: education, engineering, entertainment, and medicine. Overall, $81 \%$ of the articles discussed $\mathrm{BCI}$ in medicine areas because rehabilitation is synonymous with health and medical care. While the engineering area covered approximately $10 \%$ of the total articles, some articles proposed BCI systems to assist while drive the vehicles [33]. The engineering area here does not focus on medical purposes such as on controlling the drone or vehicles [34]. Further, $6 \%$ and $3 \%$ of the articles were based on the entertainment and education areas [35], respectively.

A total of 28 companies were identified from the selected studies in this SLR. Figure 5 presents information on the EEG equipment in the selected studies and their companies. According to Figure 5, the g.Tec company leads with 60 articles. One of the reasons many studies used the equipment of g.Tec is that this company has four headquarters in Austria, Spain, USA, and Hong Kong (https: / /www.gtec.at/, accessed on 25 February 2021) which can be easily obtained and purchased and at the same time can match the power consumption in different countries. The equipment from Emotiv company was used in 49 articles and that from Compumedics Neuroscan company was used in 29 articles. The equipment of Brain Products, NeuroSky, and OpenBCI was used in 20,15, and 10 articles, respectively. The equipment of the rest of the companies was less, i.e., 10 articles. 


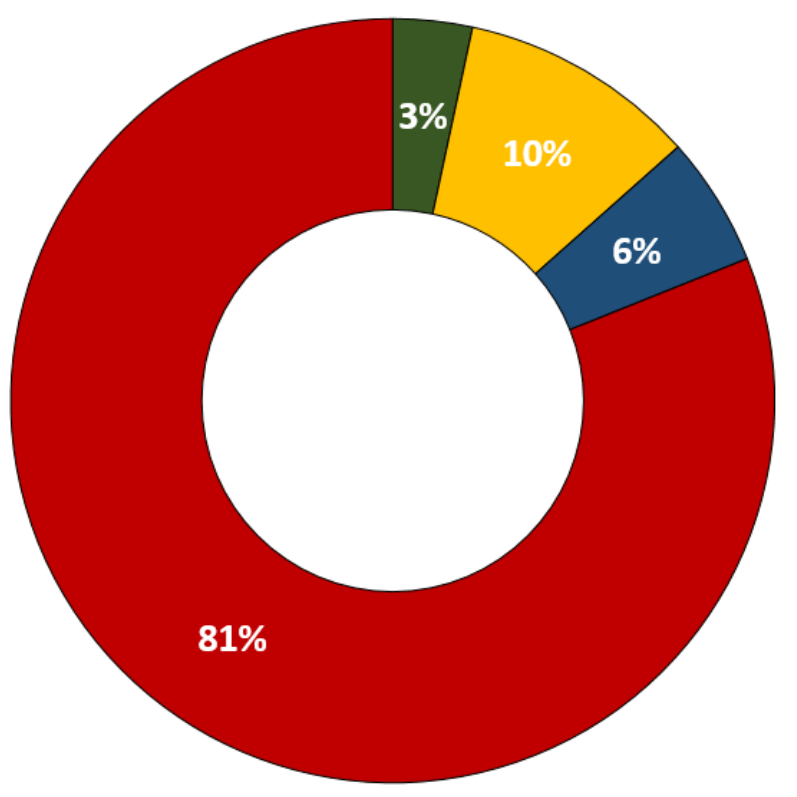

$\square$ Education $\square$ Engineering $\square$ Entertainment $\square$ Medical

Figure 4. Proportion chart of published article research areas based on noninvasive BCI technology.

\begin{tabular}{|c|c|c|c|c|}
\hline \multirow[t]{2}{*}{ Company } & \multicolumn{4}{|c|}{ Research Area } \\
\hline & Education & Engineering & Entertainment & Medicine \\
\hline Advanced Brain Monitoring & 0 & 1 & 1 & 2 \\
\hline ANT Neuro & 0 & 0 & 1 & 1 \\
\hline BIOPAC Systems Inc & 0 & 0 & 0 & 1 \\
\hline Biosemi & 0 & 0 & 1 & 7 \\
\hline Brain Products & 0 & 3 & 1 & 16 \\
\hline Cognionics Inc & 0 & 1 & 0 & 1 \\
\hline Compumedics Neuroscan & 0 & 2 & 3 & 24 \\
\hline Electrical Geodesics Inc & 0 & 1 & 0 & 1 \\
\hline Emotiv & 5 & 8 & 3 & 33 \\
\hline g.Tec & 0 & 5 & 1 & 54 \\
\hline InteraXon & 3 & 0 & 0 & 3 \\
\hline Jingahi & 0 & 0 & 0 & 1 \\
\hline Jordan NeuroScience Inc. & 0 & 0 & 0 & 1 \\
\hline Laxtha Inc & 0 & 0 & 0 & 1 \\
\hline Medical Computer Systems & 0 & 0 & 0 & 5 \\
\hline Medicom MTD & 0 & 0 & 0 & 3 \\
\hline Mega Electronic & 0 & 0 & 0 & 1 \\
\hline MindMedia & 0 & 0 & 0 & 1 \\
\hline NCC Medical Co. & 0 & 0 & 0 & 1 \\
\hline NeuroBioLab & 0 & 0 & 0 & 1 \\
\hline Netech & 0 & 0 & 0 & 1 \\
\hline Neuroelectrics & 0 & 1 & 0 & 8 \\
\hline NeuroSky & 0 & 2 & 0 & 13 \\
\hline Nihon Kohden & 0 & 0 & 0 & 2 \\
\hline OpenBCl & 0 & 0 & 2 & 8 \\
\hline TMSi & 0 & 0 & 0 & 1 \\
\hline VIASYS Healthcare & 0 & 0 & 0 & 1 \\
\hline Wearable Sensing & 0 & 0 & 0 & 1 \\
\hline
\end{tabular}

Figure 5. Mapping between the companies and research areas identified in the selected articles. Different colors represent the proportions of the reviewed studies, as shown by the indicators. 
The details of each research area and the equipment from different companies are:

Education: Only eight articles were found in this area with two companies. Five articles used Emotiv equipment [36-40] and another three articles used the equipment from InteraXon company [41-43].

Engineering: This is the second highest research area in this SLR, with 24 articles and 9 companies. Eight articles used Emotiv equipment [5,44-50], five articles used g.Tec equipment [51-55], three articles used Brain Products equipment [56-58], two articles used Compumedics Neuroscan equipment [59,60], and two articles used NeuroSky equipment [61,62]. For the equipment for Cognionics Inc. [63], Electrical Geodesics Inc. [64], Neuroelectrics [65], and Advanced Brain Monitoring [66], one article each used their equipment.

Entertainment: Only 13 articles were discussed in this area. Compumedics Neuroscan [67-69], and Emotiv [70-72] equipment was employed in three articles each. Two articles used OpenBCI equipment [73,74] and one article each used the equipment of Biosemi [75], g.Tec [76], ANT Neuro [77], Brain Products [78], and Advance Brain Monitoring [79].

Medical: This is the most popular research area in this SLR, with 193 articles. g.Tec equipment was used in 54 articles for the EEG method [80-133], 33 articles used Emotiv equipment [134-166], and 24 articles used Compumedics Neuroscan equipment [167-190]. Further, 16 articles used Brain Products equipment [191-206], 13 articles used NeuroSky equipment [207-219], and Neuroelectrics [220-227] and OpenBCI [228-235] equipment were used in eight articles each. Moreover, seven articles used Biosemi equipment [236-242], and four articles used Medical Computer Systems equipment [243-246]. Three articles used Medicom MTD equipment [247-249], and another three articles used the equipment from InteraXon company [250-252]. Two articles each used Advanced Brain Monitoring [253,254] and Nihon Kohden [255,256] equipment. One article each used the equipment of Mega Electronic [257], Jordan NeuroScience Inc. [258], BIOPAC Systems Inc. [259], Laxtha Inc. [260], TMSi [261], NeuroBioLab [262], Cognionics Inc. [263], Jingahi [264], VIASYS Healthcare [265], ANT Neuro [266], Wearable Sensing [267], Netech [268], MindMedia [269], NCC Medical Co. [270], and Electrical Geodesics Inc. [271].

RQ2: What are the most common types (wired or wireless) of noninvasive EEG-based BCI equipment that have been used in brain studies?

Figure 6 illustrates the proportion chart of wired EEG equipment. Overall, 45 articles used the wired equipment from the g.Tec company, followed by Compumedics Neuroscan and Brain Products, with 29 and 18 articles, respectively. The fourth popular brand of wired equipment was Biosemi, with eight articles. Figure 7 illustrates the proportion chart of wireless EEG equipment. Most articles used the wireless equipment of Emotiv, with 49 articles. The second highest were g.Tec and NeuroSky, each with 15 articles. Only two companies provided both types of EEG equipment, namely, Brain Products and g.Tec. The rest of the companies either provided wired or wireless equipment for BCI, and the devices could communicate with the brain using either wired or wireless models. The wired model is a standard system, whereas the wireless model is an evolving solution. Many companies have designed portable headsets to provide greater comfort at a low cost [272]. 


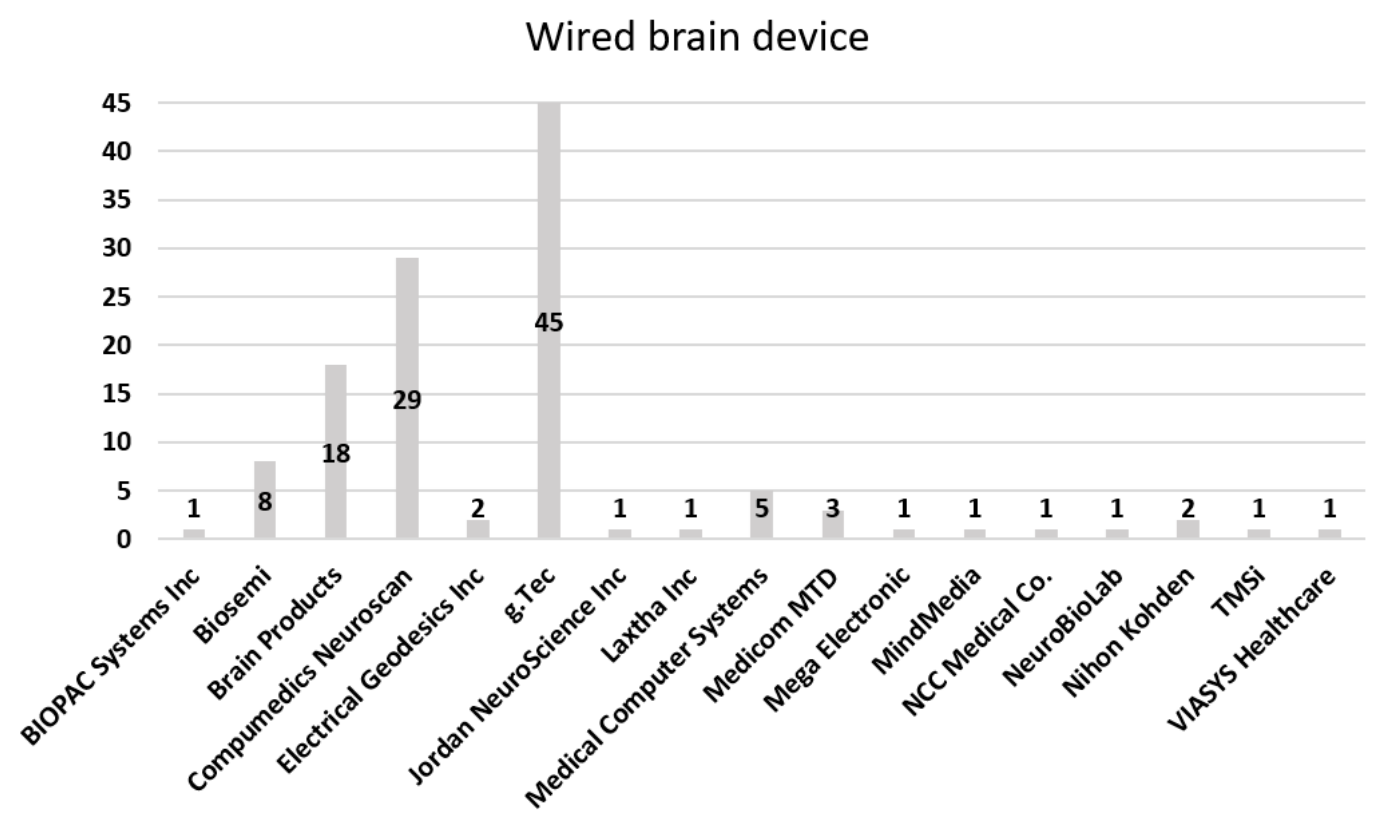

Figure 6. Proportion of companies that used noninvasive-wired equipment.

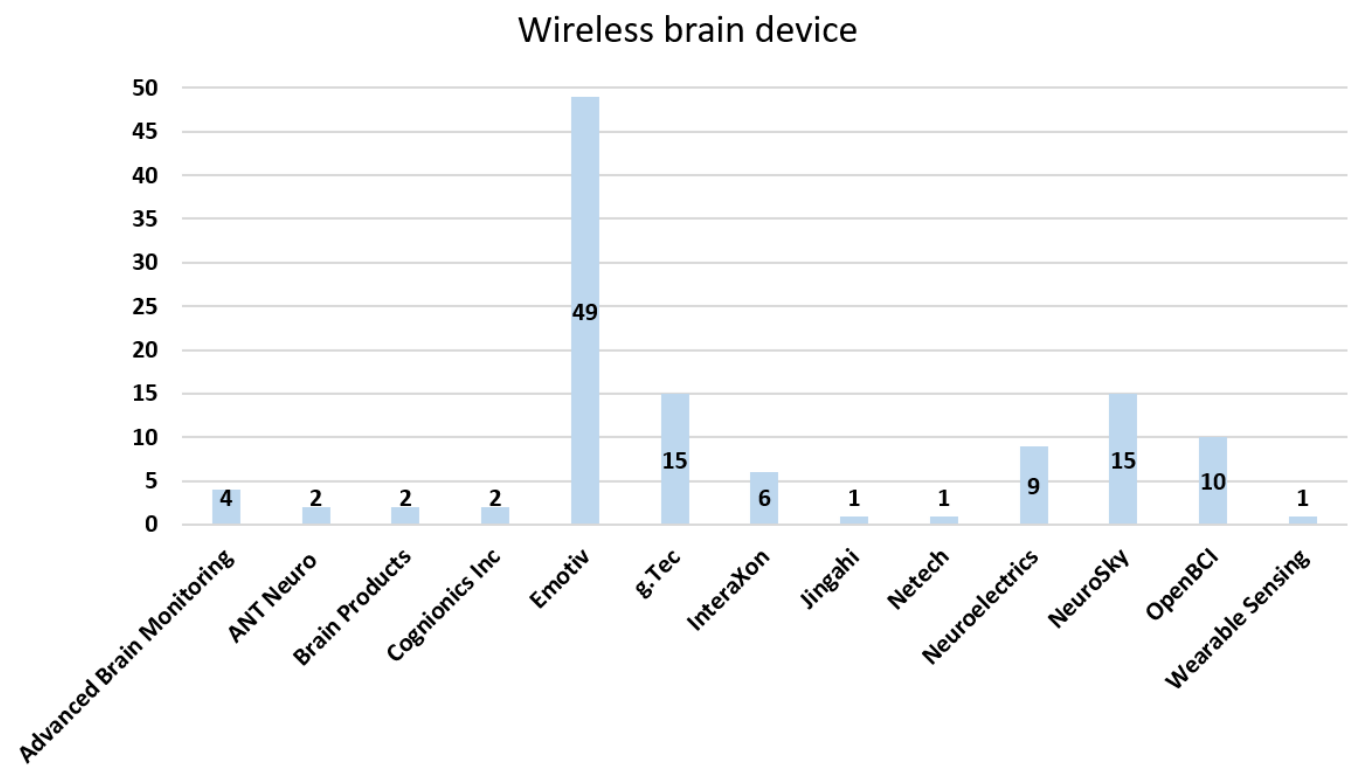

Figure 7. Proportion chart of companies that used noninvasive wireless equipment.

Table 2 summarizes the companies and their equipment, which were used in specific research areas. In Table 2, the SLR is divided into three main categories: company name ( $n=28$ ), the type of EEG equipment (wired or wireless), and research area (education, engineering, entertainment, and medicine). Furthermore, only the wireless equipment from Emotiv company covered all four research areas, even though the sector of Emotiv mostly offers entertainment options and performance (http: / / bnci-horizon-2020.eu/ images/bncih2020/FBNCI_Roadmap.pdf, accessed on 25 February 2021). 
Table 2. Types of EEG equipment for each company.

\begin{tabular}{|c|c|c|c|}
\hline \multirow{2}{*}{ Company } & \multicolumn{2}{|c|}{ Type of EEG Equipment } & \multirow{2}{*}{ Research Area } \\
\hline & Wired & Wireless & \\
\hline \multirow{2}{*}{ Advanced Brain Monitoring } & \multirow{2}{*}{$\times$} & B-Alert ${ }^{\circledR} \mathrm{X} 10$ & EG [66], MD [253,254] \\
\hline & & B-Alert X24 & ET $[79]$ \\
\hline \multirow{2}{*}{ ANT Neuro } & \multirow{2}{*}{$x$} & eegosports & ET [77] \\
\hline & & $\mathrm{eego}^{\mathrm{TM}} \mathrm{rt}$ & MD [266] \\
\hline BIOPAC Systems Inc. & EEG100C & $x$ & MD [259] \\
\hline Biosemi & ActiveTwo & $\times$ & ET [75], MD [236-242] \\
\hline \multirow{8}{*}{ Brain Products } & \multirow{8}{*}{$\begin{array}{l}\text { actiCAP system } \\
\text { actiHamp } \\
\text { BrainAmp } \\
\text { BrainVision } \\
\text { capTrak } \\
\text { QuickAmp USB }\end{array}$} & & MD $[194,199,205]$ \\
\hline & & & MD $[192,198,201,203]$ \\
\hline & & & EG [57], ET [78], MD [195-197,200,204] \\
\hline & & & EG [58] \\
\hline & & & MD [206] \\
\hline & & & EG [56] \\
\hline & & V-amp & MD [191] \\
\hline & & MOVE system & MD [193] \\
\hline \multirow{2}{*}{ Cognionics Inc. } & \multirow{2}{*}{$\times$} & HD-72 EEG & EG [63] \\
\hline & & Quick-20 & MD [263] \\
\hline \multirow{3}{*}{ Compumedics Neuroscan } & Grael & & ET $[67,68], \mathrm{MD}[187,188]$ \\
\hline & NuAmps & $x$ & MD [167-170,172,176,180,183,185,186,189,190] \\
\hline & SynAmps & & $\begin{array}{l}\text { EG [59,60], ET [69], MD [171,173-175,177-179, } \\
181,182,184]\end{array}$ \\
\hline Electrical Geodesics Inc. & Geodesic EEG System 400 & $\times$ & EG [64], MD [271] \\
\hline \multirow[t]{2}{*}{ Emotiv } & \multirow[t]{2}{*}{$\times$} & Emotiv EPOC & $\begin{array}{l}\text { ED }[37,39,40], \text { EG [5,44-50], ET [70-72], } \\
\text { MD }[134-160,162,164-166]\end{array}$ \\
\hline & & Emotiv Insight & $\operatorname{ED}[36,38], \mathrm{MD}[161,163]$ \\
\hline \multirow{6}{*}{ g.Tec } & \multirow{6}{*}{$\begin{array}{l}\text { g.BSamp } \\
\text { g.Hiamp } \\
\text { g.USBamp }\end{array}$} & & MD [110] \\
\hline & & & MD $[85,97,100,106,127,132]$ \\
\hline & & & $\begin{array}{l}\text { EG }[52,54], \text { ET [76], MD }[80-84,87,89,92,94- \\
96,98,99,101,102,104,105,107,108,111,112,114, \\
117-122,125,126,128,130,131,133]\end{array}$ \\
\hline & & g.MOBIlab $+{ }^{\circledR}$ & MD $[86,93,103,113,115,129]$ \\
\hline & & g.Nautilus & EG [51], MD [88,90,91,109,116,123,124] \\
\hline & & Unicorn Hybrid Black & EG [55] \\
\hline InteraXon & $\times$ & Muse headband & ED [41-43], MD [250-252] \\
\hline Jingahi & $\times$ & JAGA16 & MD [264] \\
\hline Jordan NeuroScience Inc. & BrainNet & $\times$ & MD [258] \\
\hline Laxtha Inc. & PolyG-I & $\times$ & MD [260] \\
\hline Medical Computer Systems & NVX52 & $\times$ & MD [243-246] \\
\hline Medicom MTD & Encephalan-EEGR-19/26 & $\times$ & MD [247-249] \\
\hline Mega Electronic & NeurOne & $\times$ & MD [257] \\
\hline MindMedia & Nexus10 Biosignal & $\times$ & MD [269] \\
\hline NCC Medical Co., & NGERP-P & $\times$ & MD [270] \\
\hline NeuroBioLab & NBL640 & $\times$ & MD [262] \\
\hline Netech & $\times$ & MinSim300 & MD [268] \\
\hline \multirow{4}{*}{ Neuroelectrics } & \multirow{4}{*}{$x$} & Enobio 8 & EG [65], MD [220,223,224,226] \\
\hline & & Enobio 32 & MD [227] \\
\hline & & StarSim 8 & MD [222] \\
\hline & & StarSim R32 & MD $[221,225]$ \\
\hline & & BrainWave & MD $[208,210]$ \\
\hline NeuroSky & $x$ & MindFlex & MD [219] \\
\hline Neurosky & $x$ & MindWave Mobile & EG [61,62], MD [207,209,211-214,216-218] \\
\hline & & ThinkGear AM (TGAM) & $\operatorname{MD}[215]$ \\
\hline Nihon Kohden & JE-921A & $x$ & MD [256] \\
\hline Ninon Konden & AB-611J & $x$ & $\operatorname{MD}[255]$ \\
\hline & & OpenBCI 32 bit & $\operatorname{MD}[232,235]$ \\
\hline OpenBCI & $x$ & Open BCI Cyton & ET $[73,74], \operatorname{MD}[228,229,231,234]$ \\
\hline & & OpenBCI Ganglion & MD [233] \\
\hline & & Ultracortex BCI & MD [230] \\
\hline TMSi & Refa 32 & $\times$ & MD [261] \\
\hline VIASYS Healthcare & Nicolet 1 & $\times$ & MD [265] \\
\hline Wearable Sensing & $x$ & DSI-24 & MD [267] \\
\hline
\end{tabular}


Overall, 17 companies provided more than two brands/products with different characteristics. For example, the company Neuroelectrics offers Enobio 8 and Enobia 32, which have up to 8 and 32 channels for EEG recording, respectively (https:/ / www.neuroelectrics. com, accessed on 25 February 2021). Therefore, researchers can select the necessary equipment based on their specific goals, including user acceptance, usability, and performance. The education research area used the wireless equipment from two companies: Emotiv (Emotiv EPOC and Emotiv Insight) and InteraXon (Muse headband). While Augustian et al. [64] used the equipment of Electrical Geodesics Inc. to propose applications and devices for assisting forestry crane control.

Table 3 shows the comparison between EEG equipment that is used in the selected studies. The details of the information about EEG equipment were found through the company's website and some from the company's representative. Unfortunately, three pieces of EEG equipment are no longer available, which are Refa32 (TMSi) and QuickAmp USB and V-amp (Brain Products). Soufineyestani et al. [273] made the comparison and limitation of EEG sensors available in the market specially for engineers, scientists, and clinicians, to understand more about EEG equipment that can match their preference. The symbol "-" implies that it could not uncover the information for the price. Some of the equipment have to request a quotation. Additionally, the symbol " $X$ " in the Medical license represents that the company does not have the certificate for medical use. In column "Additional sensor", the " $X$ " indicates the equipment is without an additional sensor. There is a wide range of companies in the market with very different goals, driven by new applications and approaches. Each of the companies have specific goals to produce the BCI-based system. Advanced Brain Monitoring develops tools for alertness and monitoring sleep, and Emotiv focuses on the gaming and research market. Different companies target the other market sector such as Brain Products and Biosemi for research, g.Tec more on health and neurofeedback, assistive technology, and research. While Emotiv pivots on entertainment and performance (http: / / bnci-horizon-2020.eu/images/bncih2020/FBNCI_Roadmap.pdf, accessed on 25 February 2021). Based on the gathered information, each company has approximate applications for each EEG equipment in column "Recommendation" as shown in Table 3. 
Table 3. A systematic comparison of the EEG devices.

\begin{tabular}{|c|c|c|c|c|c|c|c|c|}
\hline Company & EEG Equipment & Medical Certificate & Recommendation & $\begin{array}{c}\text { Electrode Number, } \\
\text { Type and Placement }\end{array}$ & $\begin{array}{c}\text { Additional Sensor } \\
\text { (Optional) }\end{array}$ & Size and Shape (Cap) & $\begin{array}{c}\text { Approximated } 2021 \\
\text { Cost }\end{array}$ & $\begin{array}{c}\text { No. of } \\
\text { Publication }\end{array}$ \\
\hline \multirow[t]{2}{*}{$\begin{array}{l}\text { Advanced Brain } \\
\text { Monitoring }\end{array}$} & B-Alert $^{\circledR}$ X10 & $\begin{array}{l}\text { ISO } 13485 \\
\text { CE, } \\
\text { FDA }\end{array}$ & $\begin{array}{c}\text { Neuromarketing, } \\
\text { BCI, } \\
\text { identify biomarkers }\end{array}$ & $\begin{array}{l}9 \text { channels, electrolyte } \\
\text { cream, and cover } \\
\text { whole brain }\end{array}$ & $\begin{array}{l}\text { ECG, } \\
\text { EMG, } \\
\text { EOG }\end{array}$ & $\begin{array}{l}\text { Adjustable (from } \\
\text { adolescent to adult) }\end{array}$ & $\$ 9950$ up to $\$ 14,950$ & 4 \\
\hline & B-Alert X24 & & & $\begin{array}{l}20 \text { channels, electrolyte } \\
\text { cream, and cover } \\
\text { whole brain }\end{array}$ & & & & \\
\hline ANT Neuro & $\begin{array}{l}\text { eegosports } \\
\text { eego }^{\mathrm{TM}}{ }_{\mathrm{rt}}\end{array}$ & $\begin{array}{l}\text { CE, } \\
\text { FDA }\end{array}$ & $\begin{array}{c}\text { BCI, } \\
\text { neurofeedback, } \\
\text { neurorehabilitation, } \\
\text { neurogaming }\end{array}$ & $\begin{array}{l}8 \text { to } 64 \text { channels, } \\
\text { gel/soft dry and cover } \\
\text { whole brain }\end{array}$ & $\begin{array}{c}\text { EMG, } \\
\text { physiological sensor }\end{array}$ & 6 sizes & - & 2 \\
\hline BIOPAC Systems Inc. & EEG100C & $x$ & $\begin{array}{l}\text { Epilepsy, } \\
\text { tumor pathology, } \\
\text { sleep studies, } \\
\text { evoked responses, } \\
\text { cognition studies. }\end{array}$ & $\begin{array}{l}16 \text { channels, wet and } \\
\text { cover whole brain }\end{array}$ & $x$ & 4 sizes & $\$ 2000$ & 1 \\
\hline Biosemi & ActiveTwo & $x$ & $\begin{array}{l}\text { Electrophysiology } \\
\text { research }\end{array}$ & $\begin{array}{l}16 \text { to } 256 \text { channels,gel } \\
\text { and cover whole brain }\end{array}$ & $\begin{array}{l}\text { EMG, } \\
\text { ECG }\end{array}$ & 15 sizes & $€ 17,000$ up to $€ 75,000$ & 8 \\
\hline \multirow[t]{2}{*}{ Brain Products } & $\begin{array}{l}\text { actiCAP system } \\
\text { actiHamp } \\
\text { BrainAmp } \\
\text { BrainVision } \\
\text { capTrak } \\
\text { MOVE system }\end{array}$ & $x$ & $\begin{array}{c}\text { Neuroscience, } \\
\text { neurofeedback, } \\
\text { neurophysiological }\end{array}$ & $\begin{array}{l}8 \text { to } 256 \text { channels, } \\
\text { gel/dry and cover } \\
\text { whole brain }\end{array}$ & $\begin{array}{l}\text { EOG, } \\
\text { EMG }\end{array}$ & 14 sizes & $\$ 12,000$ to $\$ 28,500$ & 20 \\
\hline & $\begin{array}{l}\text { QuickAmp USB } \\
\text { V-amp }\end{array}$ & & & No long & vailable & & & \\
\hline \multirow[t]{2}{*}{ Cognionics Inc. } & HD-72 EEG & $x$ & $\begin{array}{l}\text { Neurofeedback, } \\
\text { neurodiagnostic }\end{array}$ & $\begin{array}{l}64 \text { channels, dry and } \\
\text { cover whole brain }\end{array}$ & $\begin{array}{l}\text { ECG, } \\
\text { EMG, } \\
\text { EOG, } \\
\text { RESP, } \\
\text { GSR }\end{array}$ & Adjustable & $\$ 14,500$ up to $\$ 26,000$ & 2 \\
\hline & Quick-20 & & & $\begin{array}{l}21 \text { channels, dry } \\
\text { electrode and whole } \\
\text { brain }\end{array}$ & & & & \\
\hline $\begin{array}{l}\text { Compumedics } \\
\text { Neuroscan }\end{array}$ & $\begin{array}{l}\text { Grael } \\
\text { NuAmps } \\
\text { SynAmps }\end{array}$ & FDA & $\begin{array}{l}\text { Clinical } \\
\text { neuro-diagnostics, } \\
\text { research }\end{array}$ & $\begin{array}{l}\text { up to } 256 \text { channels, } \\
\text { gel/saline and cover } \\
\text { whole brain }\end{array}$ & $\begin{array}{l}\text { EOG, } \\
\text { ECG, } \\
\text { EMG }\end{array}$ & 5 sizes & - & 29 \\
\hline
\end{tabular}


Table 3. Cont.

\begin{tabular}{|c|c|c|c|c|c|c|c|c|}
\hline Company & EEG Equipment & Medical Certificate & Recommendation & $\begin{array}{l}\text { Electrode Number, } \\
\text { Type and Placement }\end{array}$ & $\begin{array}{l}\text { Additional Sensor } \\
\text { (Optional) }\end{array}$ & Size and Shape (Cap) & $\begin{array}{c}\text { Approximated } 2021 \\
\text { Cost }\end{array}$ & $\begin{array}{c}\text { No. of } \\
\text { Publication }\end{array}$ \\
\hline $\begin{array}{l}\text { Electrical Geodesics } \\
\text { Inc. }\end{array}$ & $\begin{array}{l}\text { Geodesic EEG System } \\
400\end{array}$ & FDA & Clinical applications & $\begin{array}{l}\text { up to } 256 \text { channels, } \\
\text { saline and cover whole } \\
\text { brain }\end{array}$ & ECG & $\begin{array}{l}\text { Available in sizes from } \\
\text { infant to adult }\end{array}$ & - & 2 \\
\hline \multirow[t]{2}{*}{ Emotiv } & Emotiv EPOC & $x$ & $\begin{array}{l}\text { Research, } \\
\text { personal use }\end{array}$ & $\begin{array}{l}14 \text { channels, saline } \\
\text { soaked felt pads and } \\
\text { cover whole brain }\end{array}$ & $\begin{array}{l}\text { Quaternions, } \\
\text { accelerometer, } \\
\text { magnetometer }\end{array}$ & Adjustable & $\$ 299$ up to $\$ 849$ & 49 \\
\hline & Emotiv Insight & & & $\begin{array}{l}5 \text { channels, semi dry } \\
\text { and cover frontal, } \\
\text { temporal and parietal }\end{array}$ & & & & \\
\hline g.Tec & $\begin{array}{c}\text { g.BSamp } \\
\text { g.Hiamp } \\
\text { g.USBamp } \\
\text { g.MOBIlab+ } \\
\text { g.Nautilus } \\
\text { Unicorn Hybrid Black }\end{array}$ & $\begin{array}{l}\text { ISO } 14971 \\
\text { FDA }\end{array}$ & $\begin{array}{c}\mathrm{BCI} \\
\text { neuroscience, } \\
\text { neurotechnology }\end{array}$ & $\begin{array}{l}\text { up to } 256 \text { channels, } \\
\text { dry/gel and cover } \\
\text { whole brain }\end{array}$ & $\begin{array}{c}\text { ECoG, } \\
\text { ECG,, } \\
\text { EMG, } \\
\text { EOG, } \\
\text { accelerometer, } \\
\text { external body sensor }\end{array}$ & 3 sizes & $\begin{array}{c}€ 1000 \text { (Unicorn Hybrid } \\
\text { Black) to } \\
€ 30,000 \text { (customize) }\end{array}$ & 60 \\
\hline Jingahi & JAGA16 & $x$ & $\begin{array}{l}\text { Neuroscience, } \\
\text { suitable for rat }\end{array}$ & $\begin{array}{l}16 \text { channels and cover } \\
\text { whole brain }\end{array}$ & $x$ & Standard size & - & 1 \\
\hline Laxtha Inc. & PolyG-I & $\begin{array}{l}\text { ISO 13485, } \\
\text { KFDA }\end{array}$ & $\begin{array}{l}\text { Scientific research, } \\
\text { forensic science }\end{array}$ & $\begin{array}{l}8 \text { channels and } \\
\text { prefrontal area }\end{array}$ & $\begin{array}{l}\text { ECG, } \\
\text { EMG, } \\
\text { PPG, } \\
\text { GSR, } \\
\text { RESP }\end{array}$ & Standard size & - & 1 \\
\hline $\begin{array}{l}\text { Medical Computer } \\
\text { Systems }\end{array}$ & NVX52 & ISO 13485 & $\begin{array}{l}\text { Research for any } \\
\text { application }\end{array}$ & $\begin{array}{l}48 \text { channels,wet and } \\
\text { cover whole brain }\end{array}$ & Any biosensor & 9 sizes & $€ 4860$ & 5 \\
\hline Medicom MTD & $\begin{array}{c}\text { Encephalan-EEGR- } \\
19 / 26\end{array}$ & ISO 13485 & $\begin{array}{c}\text { Neurology, } \\
\text { neurophysiology, } \\
\text { epileptology, } \\
\text { sleep studies, } \\
\text { scientific research }\end{array}$ & $\begin{array}{l}20 \text { channels, wet and } \\
\text { cover whole brain }\end{array}$ & $\begin{array}{l}\text { EOG, } \\
\text { ECG, } \\
\text { EMG }\end{array}$ & 5 sizes & $\$ 5000$ up to $\$ 40,000$ & 3 \\
\hline
\end{tabular}


Table 3. Cont.

\begin{tabular}{|c|c|c|c|c|c|c|c|c|}
\hline Company & EEG Equipment & Medical Certificate & Recommendation & $\begin{array}{l}\text { Electrode Number, } \\
\text { Type and Placement }\end{array}$ & $\begin{array}{l}\text { Additional Sensor } \\
\text { (Optional) }\end{array}$ & Size and Shape (Cap) & $\begin{array}{c}\text { Approximated } 2021 \\
\text { Cost }\end{array}$ & $\begin{array}{c}\text { No. of } \\
\text { Publication }\end{array}$ \\
\hline Mega Electronic & NeurOne & $\begin{array}{c}\text { European Medical } \\
\text { Directive } 93 / 42 / \text { EEC, } \\
\text { ISO } 13485 \\
\text { CE }\end{array}$ & $\begin{array}{l}\text { Neuroscience, } \\
\text { psychological } \\
\text { aplication }\end{array}$ & $\begin{array}{l}32 \text { to } 128 \text { channels and } \\
\text { cover whole brain }\end{array}$ & $\begin{array}{c}\text { Gyro, } \\
\text { EMG, } \\
\text { GSR, } \\
\text { accelerometer, }\end{array}$ & Standard size & - & 1 \\
\hline MindMedia & Nexus10 Biosignal & $\begin{array}{l}\text { CE, } \\
\text { FDA }\end{array}$ & $\begin{array}{c}\text { Biofeedback, } \\
\text { neurofeedback, } \\
\text { psychophysiological } \\
\text { research. } \\
\end{array}$ & $\begin{array}{l}4 \text { channels, electrogel } \\
\text { and cover whole brain }\end{array}$ & $\begin{array}{l}\text { EMG, } \\
\text { EOG, } \\
\text { ECG }\end{array}$ & 4 sizes & $\sim € 1050$ & 1 \\
\hline Interaxon & $\begin{array}{c}\text { Muse } \\
\text { headband }\end{array}$ & $x$ & $\begin{array}{l}\text { EEG-powered sleep, } \\
\text { tracking, } \\
\text { meditation }\end{array}$ & $\begin{array}{l}2 \text { channels, dry and } \\
\text { cover frontal lobe }\end{array}$ & $\begin{array}{c}\text { Gyro, } \\
\text { PPG, } \\
\text { accelerometer }\end{array}$ & Adjustable & $\$ 294.98$ up to $\$ 369.98$ & 6 \\
\hline NCC Medical Co. & NGERP-P & ISO 13485 & - & $\begin{array}{c}24 \text { channels and cover } \\
\text { whole brain }\end{array}$ & - & Standard size & - & 1 \\
\hline NeuroBioLab & NBL640 & - & Neurobiofeedback & $\begin{array}{l}24 \text { channels, dry/gel } \\
\text { electrode and cover } \\
\text { whole brain }\end{array}$ & $x$ & Standard size & - & 1 \\
\hline Neuroelectrics & $\begin{array}{c}\text { Enobio } 8 \\
\text { Enobio } 32 \\
\text { StarSim } 8 \\
\text { StarSim R32 } \\
\end{array}$ & $\begin{array}{l}\text { CE, } \\
\text { FDA }\end{array}$ & $\begin{array}{c}\text { Neuroscience, } \\
\text { BCI, } \\
\text { neurogaming, } \\
\text { neurofeedback } \\
\end{array}$ & $\begin{array}{l}8 \text { to } 32 \text { channels, } \\
\text { dry/gel and cover } \\
\text { whole brain }\end{array}$ & Accelerometer & 6 sizes & - & 9 \\
\hline NeuroSky & $\begin{array}{c}\text { BrainWave } \\
\text { MIndFlex } \\
\text { MindWave } \\
\text { ThinkGearAM (TGAM) }\end{array}$ & $\mathrm{x}$ & $\begin{array}{c}\text { BCI, } \\
\text { neurogaming, } \\
\text { neurofeedback, } \\
\text { neuroscience, } \\
\text { meditation }\end{array}$ & $\begin{array}{l}1 \text { channel, dry and } \\
\text { cover frontal lobe }\end{array}$ & ECG & Adjustable & $\$ 109.99$ & 15 \\
\hline Nihon Kohden & $\begin{array}{l}\text { JE-921A } \\
\text { AB-611J }\end{array}$ & $\begin{array}{l}\text { ISO 13485, } \\
\text { MDSAP }\end{array}$ & $\begin{array}{l}\text { Epilepsy monitoring, } \\
\text { medical research }\end{array}$ & $\begin{array}{l}5 \text { to } 32 \text { channels and } \\
\text { cover whole brain }\end{array}$ & Oximetry & $\begin{array}{l}4 \text { sizes and } 1 \text { adjustable } \\
\text { silicone cap }\end{array}$ & - & 2 \\
\hline
\end{tabular}


Table 3. Cont.

\begin{tabular}{|c|c|c|c|c|c|c|c|c|}
\hline Company & EEG Equipment & Medical Certificate & Recommendation & $\begin{array}{l}\text { Electrode Number, } \\
\text { Type and Placement }\end{array}$ & $\begin{array}{c}\text { Additional Sensor } \\
\text { (Optional) }\end{array}$ & Size and Shape (Cap) & $\begin{array}{c}\text { Approximated } 2021 \\
\text { Cost }\end{array}$ & $\begin{array}{c}\text { No. of } \\
\text { Publication }\end{array}$ \\
\hline OpenBCI & $\begin{array}{l}\text { OpenBCI 32bit } \\
\text { Open BCI Cyton } \\
\text { OpenBCI Ganglion } \\
\text { Ultracortex BCI }\end{array}$ & $x$ & $\begin{array}{c}\text { BCI, } \\
\text { biosensing, } \\
\text { neurofeedback }\end{array}$ & $\begin{array}{l}4 \text { to } 21 \text { channels, } \\
\text { dry/gel and cover } \\
\text { whole brain }\end{array}$ & $\begin{array}{c}\text { EMG, } \\
\text { ECG, } \\
\text { accelerometer }\end{array}$ & $\begin{array}{l}3 \text { sizes and 3D } \\
\text { printable can be adjust }\end{array}$ & up to $\$ 3200$ & 10 \\
\hline TMSi & Refa 32 & \multicolumn{6}{|c|}{ No longer available } & 1 \\
\hline VIASYS Healthcare & Nicolet 1 & FDA & $\begin{array}{c}\text { Respiratory care, } \\
\text { neuroscience, } \\
\text { medical, } \\
\text { surgical care }\end{array}$ & $\begin{array}{l}32 \text { to } 44 \text { channels and } \\
\text { cover whole brain }\end{array}$ & EMG & Standard size & - & 1 \\
\hline Wearable Sensing & DSI-24 & $\mathrm{x}$ & $\begin{array}{l}\text { Psychological research, } \\
\text { neuroscience, } \\
\text { neuromarketing, } \\
\text { BCI, } \\
\text { neurogaming, } \\
\text { neurofeedback }\end{array}$ & $\begin{array}{l}21 \text { channels, dry and } \\
\text { cover whole brain }\end{array}$ & $\begin{array}{l}\text { ECG, } \\
\text { EMG, } \\
\text { EOG }\end{array}$ & Adjustable & $\tilde{\$} 20,000$ & 1 \\
\hline
\end{tabular}

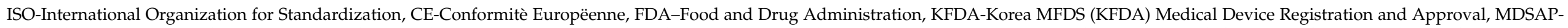

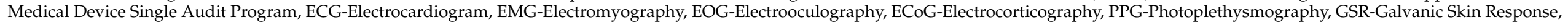

RESP-Respiratory. NB: Some EEG device prices could not be easily found from the company website. Therefore, we did not show the costs of all devices in the table 


\section{Discussion}

Several researchers are currently studying BCI technologies in different domains, such as medicine, entertainment, finance, education, and wellness. Many of the studies included in this SLR covered the medicine sector because BCIs are commonly used in assistive technologies, particularly for people with severe disabilities [121,189,274] with regard to rehabilitation and treatment. This observation is not surprising because BCIs are commonly viewed as prospects for enhancing the lives of innumerable disabled people using assistive technologies. For instance, the wearable knee exoskeleton device is used to strengthen and rehabilitate the gait and restore the movement of people with knee motion disabilities [275]. Another application is controlling wheelchairs so that paralyzed or quadriplegic patients can move around without the need for caregivers [37,214,215].

Moreover, in the field of engineering, BCIs can provide disabled and healthy people with an alternative communication medium that involves minimum movement of muscles for activities such as controlling home appliances. Even healthy people may face circumstances where they cannot use their hands to operate appliances, e.g., during cooking or dealing with hazardous materials or chemicals. Therefore, hands-free systems have been established to control home appliances [48] or control robots that can help perform house chores, such as cleaning [5]. Currently, BCI-based home appliances can only handle one application at a time, thus limiting their effectiveness in real-world circumstances. Future research is needed to overcome this issue.

The prospect of $\mathrm{BCI}$ is applicable to both indoor and outdoor applications. The outdoor applications include helping security teams explore opponent areas for safety and security $[50,276]$. Other innovations using the $\mathrm{BCI}$ technology influence researchers to use BCIs as a part of daily life, such as controlling vehicles for assistance in remote driving [49]. With this approach, BCIs can help in programming vehicles for self driving whenever the vehicle detects that the driver feels drowsy or tired.

Nevertheless, intense attention is now centered on assistive applications meant to support healthy users, for example, in the entertainment and gaming areas. With some music, such applications can stir feelings and generate various emotional responses because music itself is a central feature of media-based entertainment [277]. Therefore, using BCI technology, music can be successfully produced based on emotion-based qualities using EEG data. However, there are some challenges when producing the same music for different people. For example, two people in one room may feel excited when listening to the same music; however, there is the possibility that one of them may not like the music. Hence, personal preferences also affect this sector.

Additionally, research on the use of BCI for gaming is increasing in the entertainment industry. Laar et al. [278] discussed the performance and experience of gaming using BCI equipment. Nevertheless, BCIs are radically different from other input devices, such as keyboards and mice, as they offer users alternative input channels for controlling games. Moreover, BCIs can assist players in being more engaged with games [71]. Some companies have established BCI games, and some BCI companies engage in game production, such as NeuroSky, Emotiv, and MindGames. Furthermore, games can help in rehabilitation and people can enjoy them and feel entertained. Vega et al. [70] proposed a game for controlling video games using prosthetic devices and Rashid et al. [61] proposed a game for increased attention, particularly for people with attention deficit disorder. However, the challenge in implementing BCIs in gaming can be the user experience. Wearing another device on the head can be uncomfortable for some users who play games for a long duration.

Further, BCIs can be tools for students to increase their learning ability and for educators to further understand their students. A BCI can analyze a student's cognitive states, assess the information and visualizations to be used, and change the training method to respond to a student's individual learning needs [38]. Furthermore, a BCI can help students refocus and increase their interest and engagement in the learning process [40]. The neurofeedback system in BCIs can help teachers to better observe and understand students, and it can aid them in customizing their approach based on a student's needs. 
The Unicorn Hybrid Black brand of the g.Tec company was specifically designed for the education area. However, none of the articles discussed here used the Unicorn Hybrid Black equipment in the education area. The issues regarding BCI and education are mainly concerned with the costs of providing all students with the necessary equipment and collecting their EEG data and disturbances attributed to external variables, such as shifting students' attention and noise in the class environment.

Furthermore, when the various industries' potential expands, like entertainment and education, many companies join the market with very different objectives influenced by the emerging market sectors and approaches. Not all companies design conventional BCI systems; however, investments in consumer goods would undoubtedly and significantly affect the infrastructure, price, and usability for the BCI systems (http:/ / bnci-horizon-2020.eu/images/bncih2020/FBNCI_Roadmap.pdf, accessed on 25 February 2021). Some companies provide both wired and wireless systems, and some companies only focus on developing and designing wireless equipment, such as InteraXon, Emotiv, and Neuroelectrics. Over the decades, the EEG hardware technology has also advanced. Many wireless multichannel devices have been developed, offering high-quality EEG and physiological signals in more straightforward, compact, and comfortable configurations compared with conventional complicated systems. Wireless systems are more convenient for users because they facilitate free movement. Moreover, wireless equipment has proven to be suitable for clinical trials [279]. However, some challenges need to be addressed regarding EEG equipment in sensor development. Not many researchers are deeply engaged in studying the BCI sensor design because it is generally a very complicated subject [280]. Sensors are applied to both wired and wireless equipment because they are attached to the human head. The electrode position must be accurate. Furthermore, the sensor material must be selected appropriately to avoid any side effect.

\section{Limitation}

This SLR may have several limitations that can impact its overall quality

- Other digital libraries could have been used in the search for studies, which may impact candidate studies. However, we selected the largest libraries that deal with the SLR's topic. Using other libraries may have just resulted in more duplicates.

- Herein, the number of selected studies can impact the conclusion drawn. The studies are pertaining to the medicine sector because of the keyword "rehab*". However, we included two other keywords related to other sectors in the search string.

- This review mainly focused on English publications; however, there could be relevant publications in other languages.

\section{Conclusions}

Assistive technology can benefit people with cognitive problems and physical impairments. In this review, a variety of equipment that can be successfully implemented using BCIs in four sectors (i.e., education, engineering, entertainment, and medicine) is highlighted. Overall, the EEG channel is a reference for adapting the technology based on different levels of impairments and disabilities. Moreover, rehabilitation can help people increase their independence using BCIs.

Based on the obtained results, numerous studies were biased toward the medicine sector. However, with further research and experiments, this trend can also be observed for the other sectors. EEG data could be efficiently obtained from all four research areas. Moreover, EEG devices can be used by healthy people, not only by people with disabilities. With an increasing number of wireless devices, EEG can be recorded in many natural ways in daily life, such as in crowded places or during exercise.

We do believe that using relatively expensive EEG devices that have FDA certificate in developing medical $\mathrm{BCI}$ applications is mandatory rather than using cheap portable devices due to their high quality signals in terms of signal-noise ratio (SNR) and spatio-temporal resolutions. For developing noninvasive BCI applications, investigators can refer to market 
size to decide which research studies to support. Nowadays, the BCI market is large and popular in terms of gaming applications. The manufacturer of the game console and some game developers can integrate with a BCI-based gaming device. For BCI technology to succeed and gain wide adoption, affordability should be guaranteed and focus on specific end-user products based on market demand for $\mathrm{BCI}$ investors (researchers) to decide which devices to select for the application. Wireless devices are more comfortable to move around and suitable for long-term use in daily life and outdoor applications. Additional, dry EEG electrode is easy to use and does not require additional instruments like syringes and there is no need to wash the head afterward.

Furthermore, a limited number of studies have reported using $\mathrm{BCI}$ in the engineering area, suggesting more room for exploration. With COVID-19, using EEG-based robot or drone control can explore and detect the location of the virus. The rationale is to reduce the risk of exposure of COVID-19 to the people. Next, in the entertainment sector, rather than focusing only on games, EEG-based BCI can predict the market for the movie genres (e.g., which genre can give more excitement to the audience). In the same way, portable EEG devices are important in neuro-education. Due to COVID-19, all the schools and institutes were closed and were instructed to perform distance learning. When studying online, the optimal learning strategy can be determined by analyzing the behavior of student brains.

The BCI-based system can expand into the new market, which gives more significant opportunities by merging the current market with another field, such as medicine, with the robotic sector to reduce overall healthcare costs. Due to EEG devices' widespread availability and becoming portable, the treatment and rehabilitation are not limited to the hospital but may also occur in the home. Another instance is engineering with the automotive and aerospace sectors for people's safety in the road or outer space. Diverse considerations should be made before choosing and purchasing a suitable device.

Numerous factors need to be considered for selecting the devices such as medical certificate, electrode type (dry/saline/gel), size and shape for the cap, and type of devices (wired/wireless). The applications specific to medical and clinical treatment need approval. Kasim et al. [281] mentioned the dry electrode exhibited a greater resistance to line noise. Using several different sizes and shapes (cap) for head size variability experiments and studies can increase the overall price because of the need to buy more than one cap. Li et al. [282] mentioned that the wired EEG devices give better quality but are more expensive, while wireless devices are more convenient for daily life application [283]. The wireless device was suited for underlying cognitive processes and body motion such as sport science and physical therapy.

More user-experience evaluations and data-integrity policies are required to ensure that the needs and preferences of the end users are met and that their personal data are secured. Therefore, the obtained findings can impact policymakers with regard to using EEG devices, particularly wireless devices, to prevent data from being stolen and for researchers to explore new sectors to adapt the BCI technology.

Moreover, SLR results provide directions for future research. In future studies, we intend to measure the user experience based on different devices to identify the extra features of each EEG equipment and determine which of them is suitable for each sector.

Author Contributions: A.N.B. made the overall conceptual design for this systematic literature review and contributed to analyzing results, drafting, and editing the manuscript. N.J. contributed to collecting articles, analyzing results, and drafting the manuscript. S.O. and A.L. contributed to editing the manuscript. All authors listed have made a substantial, direct, and intellectual contribution to the work and approved it for publication. All authors have read and agreed to the published version of the manuscript.

Funding: The research reported in this publication was supported in part by United Arab Emirates University Start-up grant G00003270 (31T130).

Institutional Review Board Statement: Not applicable. 
Informed Consent Statement: Not applicable.

Data Availability Statement: Data generated from the IEEE digital library, PubMed, Scopus, and ScienceDirect at UAEU, available upon request.

Conflicts of Interest: The authors declare no conflict of interest.

\section{References}

1. Belkacem, A.N.; Jamil, N.; Palmer, J.A.; Ouhbi, S.; Chen, C. Brain computer interfaces for improving the quality of life of older adults and elderly patients. Front. Neurosci. 2020, 14, 692. [CrossRef]

2. Pineda, J.A.; Allison, B.; Vankov, A. The effects of self-movement, observation, and imagination on/spl mu/rhythms and readiness potentials (RP's): Toward a brain-computer interface (BCI). IEEE Trans. Rehabil. Eng. 2000, 8, 219-222. [CrossRef]

3. Belkacem, A.N.; Nishio, S.; Suzuki, T.; Ishiguro, H.; Hirata, M. Neuromagnetic decoding of simultaneous bilateral hand movements for multidimensional brain-machine interfaces. IEEE Trans. Neural Syst. Rehabil. Eng. 2018, 26, 1301-1310. [CrossRef]

4. Zgallai, W.; Brown, J.T.; Ibrahim, A.; Mahmood, F.; Mohammad, K.; Khalfan, M.; Mohammed, M.; Salem, M.; Hamood, N. Deep learning AI application to an EEG driven BCI smart wheelchair. In Proceedings of the 2019 Advances in Science and Engineering Technology International Conferences (ASET), Dubai, United Arab Emirates, 26 March-10 April 2019; pp. 1-5.

5. Shao, L.; Zhang, L.; Belkacem, A.N.; Zhang, Y.; Chen, X.; Li, J.; Liu, H. EEG-controlled wall-crawling cleaning robot using SSVEP-based brain-computer interface. J. Healthc. Eng. 2020, 2020, 6968713. [CrossRef]

6. Wolpaw, J.; Wolpaw, E.W. Brain-Computer Interfaces: Principles and Practice; Oxford University Press: New York, NY, USA, 2012.

7. Gao, Q.; Dou, L.; Belkacem, A.N.; Chen, C. Noninvasive electroencephalogram based control of a robotic arm for writing task using hybrid BCI system. BioMed Res. Int. 2017, 2017, 8316485. [CrossRef]

8. Fazel-Rezai, R.; Allison, B.Z.; Guger, C.; Sellers, E.W.; Kleih, S.C.; Kübler, A. P300 brain computer interface: Current challenges and emerging trends. Front. Neuroeng. 2012, 5, 14. [CrossRef]

9. Sellers, E.W.; Vaughan, T.M.; Wolpaw, J.R. A brain-computer interface for long-term independent home use. Amyotroph. Lateral Scler. 2010, 11, 449-455. [CrossRef]

10. Cincotti, F.; Mattia, D.; Aloise, F.; Bufalari, S.; Schalk, G.; Oriolo, G.; Cherubini, A.; Marciani, M.G.; Babiloni, F. Non-invasive brain-computer interface system: Towards its application as assistive technology. Brain Res. Bull. 2008, 75, 796-803. [CrossRef]

11. Pires, G.; Torres, M.; Casaleiro, N.; Nunes, U.; Castelo-Branco, M. Playing Tetris with non-invasive BCI. In Proceedings of the 2011 IEEE 1st International Conference on Serious Games and Applications for Health (Segah), Braga, Portugal, 16-18 November 2011; pp. 1-6.

12. Congedo, M.; Goyat, M.; Tarrin, N.; Ionescu, G.; Varnet, L.; Rivet, B.; Phlypo, R.; Jrad, N.; Acquadro, M.; Jutten, C. “Brain Invaders": A prototype of an open-source P300-based video game working with the OpenViBE platform. In Proceedings of the 5th International Brain-Computer Interface Conference 2011 (BCI 2011), Graz, Austria, 22-24 September 2011; pp. $280-283$.

13. Kryger, M.; Wester, B.; Pohlmeyer, E.A.; Rich, M.; John, B.; Beaty, J.; McLoughlin, M.; Boninger, M.; Tyler-Kabara, E.C. Flight simulation using a Brain-Computer Interface: A pilot, pilot study. Exp. Neurol. 2017, 287, 473-478. [CrossRef] [PubMed]

14. Prashant, P.; Joshi, A.; Gandhi, V. Brain computer interface: A review. In Proceedings of the 2015 5th Nirma University International Conference on Engineering (NUiCONE), Ahmedabad, India, 26-28 November 2015; pp. 1-6.

15. Kübler, A.; Neumann, N.; Kaiser, J.; Kotchoubey, B.; Hinterberger, T.; Birbaumer, N.P. Brain-computer communication: Selfregulation of slow cortical potentials for verbal communication. Arch. Phys. Med. Rehabil. 2001, 82, 1533-1539. [CrossRef]

16. Zickler, C.; Halder, S.; Kleih, S.C.; Herbert, C.; Kübler, A. Brain painting: Usability testing according to the user-centered design in end users with severe motor paralysis. Artif. Intell. Med. 2013, 59, 99-110. [CrossRef] [PubMed]

17. Birbaumer, N.; Ghanayim, N.; Hinterberger, T.; Iversen, I.; Kotchoubey, B.; Kübler, A.; Perelmouter, J.; Taub, E.; Flor, H. A spelling device for the paralysed. Nature 1999, 398, 297-298. [CrossRef] [PubMed]

18. Mondal, D.D.; Alagirisamy, D.M. Brain Computer Interface (BCI): Mechanism and Challenges-A Survey. Int. J. Pharm. Res. 2020, 12, 2200-2208

19. Wilson, J.A.; Felton, E.A.; Garell, P.C.; Schalk, G.; Williams, J.C. ECoG factors underlying multimodal control of a brain-computer interface. IEEE Trans. Neural Syst. Rehabil. Eng. 2006, 14, 246-250. [CrossRef]

20. Rezeika, A.; Benda, M.; Stawicki, P.; Gembler, F.; Saboor, A.; Volosyak, I. Brain-computer interface spellers: A review. Brain Sci. 2018, 8, 57. [CrossRef]

21. Hwang, H.J.; Kwon, K.; Im, C.H. Neurofeedback-based motor imagery training for brain-computer interface (BCI). J. Neurosci. Methods 2009, 179, 150-156. [CrossRef]

22. Lum, P.S.; Burgar, C.G.; Shor, P.C.; Majmundar, M.; Van der Loos, M. Robot-assisted movement training compared with conventional therapy techniques for the rehabilitation of upper-limb motor function after stroke. Arch. Phys. Med. Rehabil. 2002, 83, 952-959. [CrossRef]

23. Remsik, A.; Young, B.; Vermilyea, R.; Kiekhoefer, L.; Abrams, J.; Evander Elmore, S.; Schultz, P.; Nair, V.; Edwards, D.; Williams, J.; et al. A review of the progression and future implications of brain-computer interface therapies for restoration of distal upper extremity motor function after stroke. Expert Rev. Med Devices 2016, 13, 445-454. [CrossRef] 
24. Ramos-Murguialday, A.; Broetz, D.; Rea, M.; Läer, L.; Yilmaz, Ö.; Brasil, F.L.; Liberati, G.; Curado, M.R.; Garcia-Cossio, E.; Vyziotis, A.; et al. Brain-machine interface in chronic stroke rehabilitation: A controlled study. Ann. Neurol. 2013, 74, 100-108. [CrossRef] [PubMed]

25. Henderson, S.; Skelton, H.; Rosenbaum, P. Assistive devices for children with functional impairments: Impact on child and caregiver function. Dev. Med. Child Neurol. 2008, 50, 89-98. [CrossRef]

26. Demers, L.; Fuhrer, M.J.; Jutai, J.; Lenker, J.; Depa, M.; De Ruyter, F. A conceptual framework of outcomes for caregivers of assistive technology users. Am. J. Phys. Med. Rehabil. 2009, 88, 645-655. [CrossRef] [PubMed]

27. Shute, V.J.; Zapata-Rivera, D. Adaptive technologies. ETS Res. Rep. Ser. 2007, 2007, i-34. [CrossRef]

28. Zhang, L. A web-based English teaching module on the administration of electroencephalography-based neurofeedback training for Chinese students. NeuroQuantology 2018, 16. [CrossRef]

29. Chiang, H.S.; Hsiao, K.L.; Liu, L.C. EEG-based detection model for evaluating and improving learning attention. J. Med. Biol. Eng. 2018, 38, 847-856. [CrossRef]

30. Liberati, A.; Altman, D.G.; Tetzlaff, J.; Mulrow, C.; Gøtzsche, P.C.; Ioannidis, J.P.; Clarke, M.; Devereaux, P.J.; Kleijnen, J.; Moher, D. The PRISMA statement for reporting systematic reviews and meta-analyses of studies that evaluate health care interventions: Explanation and elaboration. J. Clin. Epidemiol. 2009, 62, e1-e34. [CrossRef]

31. Cypher, D.; Chevrollier, N.; Montavont, N.; Golmie, N. Prevailing over wires in healthcare environments: Benefits and challenges. IEEE Commun. Mag. 2006, 44, 56-63. [CrossRef]

32. Horizon, B. Roadmap-The Future in Brain/Neural-Computer Interaction. Horizon 2020, 10, 978-983.

33. Babu, G.M.; Balaji, S.V.; Adalarasu, K.; Nagasai, V.; Siva, A.; Geethanjali, B. Brain computer interface for vehicle navigation. Biomed. Res. 2017, 28, 344-350

34. Chen, C.; Zhou, P.; Belkacem, A.N.; Lu, L.; Xu, R.; Wang, X.; Tan, W.; Qiao, Z.; Li, P.; Gao, Q.; et al. Quadcopter Robot Control Based on Hybrid Brain-Computer Interface System. Sens. Mater. 2020, 32, 991-1004. [CrossRef]

35. Belkacem, A.N.; Lakas, A. A case study on teaching a brain-computer interface interdisciplinary course to undergraduates. In Smart Education and e-Learning 2021; Springer: Berlin/Heidelberg, Germany, 2021; pp. 215-228.

36. Lekova, A.; Dimitrova, M.; Kostova, S.; Bouattane, O.; Ozaeta, L. Bci for assessing the emotional and cognitive skills of children with special educational needs. In Proceedings of the 2018 IEEE 5th International Congress on Information Science and Technology (CiSt), Marrakech, Morocco, 21-27 October 2018; pp. 400-403.

37. Kanagasabai, P.S.; Gautam, R.; Rathna, G. Brain-computer interface learning system for Quadriplegics. In Proceedings of the 2016 IEEE 4th International Conference on MOOCs, Innovation and Technology in Education (MITE), Madurai, India, 9-10 December 2016; pp. 258-262.

38. Arnaldo, R.M.; Iglesias, J.; Gómez, V.F.; Crespo, J.; Pérez, L.; Alonso, J.F.; Sanz, A.R. Computerized brain interfaces for adaptive learning and assessment. In International Conference on Intelligent Human Systems Integration; Springer: Berlin/Heidelberg, Germany, 2018; pp. 237-241.

39. Arana-Llanes, J.Y.; González-Serna, G.; Pineda-Tapia, R.; Olivares-Peregrino, V.; Ricarte-Trives, J.J.; Latorre-Postigo, J.M. EEG lecture on recommended activities for the induction of attention and concentration mental states on e-learning students. J. Intell. Fuzzy Syst. 2018, 34, 3359-3371. [CrossRef]

40. Zhou, Y.; Xu, T.; Cai, Y.; Wu, X.; Dong, B. Monitoring cognitive workload in online videos learning through an EEG-based brain-computer interface. In International Conference on Learning and Collaboration Technologies; Springer: Berlin/Heidelberg, Germany, 2017; pp. 64-73.

41. Crawford, C.S.; Gilbert, J.E. Neuroblock: A block-based programming approach to neurofeedback application development. In Proceedings of the 2017 IEEE Symposium on Visual Languages and Human-Centric Computing (VL/HCC), Raleigh, NC, USA, 11-14 October 2017; pp. 303-307.

42. Papakostas, M.; Tsiakas, K.; Giannakopoulos, T.; Makedon, F. Towards predicting task performance from EEG signals. In Proceedings of the 2017 IEEE International Conference on Big Data (Big Data), Boston, MA, USA, 11-14 December 2017 ; pp. $4423-4425$.

43. Mehul, A.; Cioli, N.; Crawford, C.S.; Denham, A. Position: A novice oriented dual-modality programming tool for brain-computer interfaces application development. In Proceedings of the 2019 IEEE Blocks and Beyond Workshop (B\&B), Memphis, TN, USA, 18 October 2019; pp. 27-30.

44. Rizvi, S.T.H.; Karim, M.; Gulzar, M.M.; Javed, M.Y.; Furqan, M. Implementation of electroencephalography controlled prosthetic hand. Int. J. Syst. Control Commun. 2018, 9, 136-147. [CrossRef]

45. Kim, S.; Kim, J. A novel semantically congruent audiovisual interface for assisting Brain-Machine Interface (BMI) performance enhancement. In International Conference on Human-Computer Interaction; Springer: Berlin/Heidelberg, Germany, 2019 ; pp. 165-171.

46. Abiri, R.; Borhani, S.; Kilmarx, J.; Esterwood, C.; Jiang, Y.; Zhao, X. A Usability Study of Low-Cost Wireless Brain-Computer Interface for Cursor Control Using Online Linear Model. IEEE Trans. Hum. Mach. Syst. 2020, 50, 287-297. [CrossRef] [PubMed]

47. Yu, Y.C.; Garrison, H.; Battison, A.; Gabel, L. Control of a quadcopter with hybrid brain-computer interface. In Proceedings of the 2019 IEEE International Conference on Systems, Man and Cybernetics (SMC), Bari, Italy, 6-9 October 2019; pp. $2779-2784$.

48. Karunarathne, K.; Ekanayake, H. Controlling home appliances through thought commands. In Proceedings of the 2018 18th International Conference on Advances in ICT for Emerging Regions (ICTer), Colombo, Sri Lanka, 26-29 September 2018; pp. 309-315. 
49. Yin, G.; Gong, L. Direction control and speed control combined model of motor-imagery based brain-actuated vehicle. In Proceedings of the 2017 36th Chinese Control Conference (CCC), Dalian, China, 26-28 July 2017; pp. 2210-2214.

50. Chiuzbaian, A.; Jakobsen, J.; Puthusserypady, S. Mind controlled drone: An innovative multiclass SSVEP based brain computer interface. In Proceedings of the 2019 7th International Winter Conference on Brain-Computer Interface (BCI), Gangwon, Korea, 18-20 February 2019; pp. 1-5.

51. Mezzina, G.; De Venuto, D. Smart sensors HW/SW interface based on brain-actuated personal care robot for ambient assisted living. In Proceedings of the 2020 IEEE Sensors, Rotterdam, The Netherlands, 25-28 October 2020; pp. 1-4.

52. Aricò, P.; Borghini, G.; Di Flumeri, G.; Colosimo, A.; Bonelli, S.; Golfetti, A.; Pozzi, S.; Imbert, J.P.; Granger, G.; Benhacene, R.; et al. Adaptive automation triggered by EEG-based mental workload index: A passive brain-computer interface application in realistic air traffic control environment. Front. Hum. Neurosci. 2016, 10, 539. [CrossRef] [PubMed]

53. Penaloza, C.I.; Alimardani, M.; Nishio, S. Android feedback-based training modulates sensorimotor rhythms during motor imagery. IEEE Trans. Neural Syst. Rehabil. Eng. 2018, 26, 666-674. [CrossRef]

54. Stawicki, P.; Gembler, F.; Volosyak, I. Driving a semiautonomous mobile robotic car controlled by an SSVEP-based BCI. Comput. Intell. Neurosci. 2016, 2016, 4909685. [CrossRef]

55. Al-Nuaimi, F.A.; Al-Nuaimi, R.J.; Al-Dhaheri, S.S.; Ouhbi, S.; Belkacem, A.N. Mind drone chasing using EEG-based brain computer interface. In Proceedings of the 2020 16th International Conference on Intelligent Environments (IE), Madrid, Spain, 20-23 July 2020; pp. 74-79.

56. Kangassalo, L.; Spapé, M.; Ruotsalo, T. Neuroadaptive modelling for generating images matching perceptual categories. Sci. Rep. 2020, 10, 1-10. [CrossRef]

57. Wenzel, M.A.; Bogojeski, M.; Blankertz, B. Real-time inference of word relevance from electroencephalogram and eye gaze. J. Neural Eng. 2017, 14, 056007. [CrossRef]

58. Jeong, J.H.; Shim, K.H.; Kim, D.J.; Lee, S.W. Trajectory decoding of arm reaching movement imageries for brain-controlled robot arm system. In Proceedings of the 2019 41st Annual International Conference of the IEEE Engineering in Medicine and Biology Society (EMBC), Berlin, Germany, 23-27 July 2019; pp. 5544-5547.

59. Zhao, W.; Zhang, X.; Qu, J.; Xiao, J.; Huang, Y. A virtual smart home based on EEG control. In Proceedings of the 2019 IEEE 9 th International Conference on Electronics Information and Emergency Communication (ICEIEC), Beijing, China, 12-14 July 2019; pp. 85-89.

60. Ko, L.W.; Chang, Y.; Wu, P.L.; Tzou, H.A.; Chen, S.F.; Tang, S.C.; Yeh, C.L.; Chen, Y.J. Development of a smart helmet for strategical BCI applications. Sensors 2019, 19, 1867. [CrossRef]

61. Rashid, M.; Sulaiman, N.; Mustafa, M.; Khatun, S.; Bari, B.S.; Hasan, M.J.; Al-Fakih, N.M. Investigating the possibility of brain actuated mobile robot through single-channel EEG headset. In InECCE2019; Springer: Berlin/Heidelberg, Germany, 2020; pp. 579-590.

62. Lin, W.J.; Chiu, M.C. Design a personalized brain-computer interface of legorobot assisted by data analysis method. In Transdisciplinary Engineering: A Paradigm Shift; IOS Press: Amsterdam, The Netherlands, 2017; p. 311.

63. Yang, D.; Nguyen, T.H.; Chung, W.Y. A bipolar-channel hybrid brain-computer interface system for home automation control utilizing steady-state visually evoked potential and eye-blink signals. Sensors 2020, 20, 5474. [CrossRef]

64. Augustian, M.; ur Réhman, S.; Sandvig, A.; Kotikawatte, T.; Yongcui, M.; Evensmoen, H.R. EEG analysis from motor imagery to control a forestry crane. In International Conference on Intelligent Human Systems Integration; Springer: Berlin/Heidelberg, Germany, 2018; pp. 281-286.

65. Shantala, C.; Rashmi, C. Mind controlled wireless robotic arm using brain computer interface. In Proceedings of the 2017 IEEE International Conference on Computational Intelligence and Computing Research (ICCIC), Coimbatore, India, 14-16 December 2017; pp. 1-8.

66. Akinola, I.; Chen, B.; Koss, J.; Patankar, A.; Varley, J.; Allen, P. Task level hierarchical system for BCI-enabled shared autonomy. In Proceedings of the 2017 IEEE-RAS 17th International Conference on Humanoid Robotics (Humanoids), Birmingham, UK, 15-17 November 2017; pp. 219-225.

67. Wang, J.; Wang, W.; Hou, Z.G.; Shi, W.; Liang, X.; Ren, S.; Peng, L.; Zhou, Y.J. BCI and multimodal feedback based attention regulation for lower limb rehabilitation. In Proceedings of the 2019 International Joint Conference on Neural Networks (IJCNN), Budapest, Hungary, 14-19 July 2019; pp. 1-7.

68. Wang, J.; Wang, W.; Hou, Z.G. Toward Improving Engagement in Neural Rehabilitation: Attention Enhancement Based on Brain-Computer Interface and Audiovisual Feedback. IEEE Trans. Cogn. Dev. Syst. 2019, 12, 787-796. [CrossRef]

69. Zhao, C.; Zhang, Z.; Li, Y.; Pan, X.; Qu, J.; Yan, Z. An EEG-based mind controlled virtual-human obstacle-avoidance platform in three dimensional virtual environment. In Proceedings of the 2017 8th International IEEE/EMBS Conference on Neural Engineering (NER), Shanghai, China, 25-28 May 2017; pp. 387-390.

70. Vega, I.; Adarve, C.; Villar-Vega, H.; Páramo, C. Serious game for real-time brain-computer interface training. J. Phys. Conf. Ser. 2019, 1418, 012011. [CrossRef]

71. Carofiglio, V.; De Carolis, B.; D’Errico, F. A BCI-based Assessment of a Player's State of Mind for Game Adaptation. Available online: http:/ / ceur-ws.org/Vol-2480/GHItaly19_paper_04.pdf (accessed on 11 July 2021).

72. Langroudi, G.; Jordanous, A.; Li, L. Music emotion capture: Sonifying emotions in EEG data. In Proceedings of the Symposium on Emotion Modelling and Detection in Social Media and Online Interaction, Liverpool, UK, 4-6 April 2018. 
73. McMahon, M.; Schukat, M. A low-cost, open-source, BCI-VR prototype for real-time signal processing of EEG to manipulate 3D VR objects as a form of neurofeedback. In Proceedings of the 2018 29th Irish Signals and Systems Conference (ISSC), Belfast, UK, 21-22 June 2018; pp. 1-6.

74. McMahon, M.; Schukat, M. A low-cost, open-source, BCI-VR game control development environment prototype for game based neurorehabilitation. In Proceedings of the 2018 IEEE Games, Entertainment, Media Conference (GEM), Galway, Ireland, 15-17 August 2018; pp. 1-9.

75. Arvaneh, M.; Robertson, I.H.; Ward, T.E. A p300-based brain-computer interface for improving attention. Front. Hum. Neurosci. 2019, 12, 524. [CrossRef] [PubMed]

76. Leite, H.M.d.A.; Carvalho, S.N.d.; Costa, T.B.d.S.; Attux, R.; Hornung, H.H.; Arantes, D.S. Analysis of user interaction with a brain-computer interface based on steady-state visually evoked potentials: Case study of a game. Comput. Intell. Neurosci. 2018, 2018, 4920132. [CrossRef] [PubMed]

77. Cunha, J.D.; Scherer, R. Are online co-adaptive sensorimotor rhythm brain-computer interface training paradigms effective? In Proceedings of the 2018 International Conference on Cyberworlds (CW), Singapore, 3-5 October 2018; pp. 419-422.

78. Labonte-Lemoyne, E.; Courtemanche, F.; Louis, V.; Fredette, M.; Sénécal, S.; Léger, P.M. Dynamic threshold selection for a biocybernetic loop in an adaptive video game context. Front. Hum. Neurosci. 2018, 12, 282. [CrossRef]

79. Myrden, A.; Chau, T. Towards psychologically adaptive brain-computer interfaces. J. Neural Eng. 2016, 13, 066022. [CrossRef]

80. Adama, V.; Hoffman, J.; Bogdan, M. Coupling Brain-Computer Interface and Electrical Stimulation for Stroke Rehabilitation and Tremor Reduction in Parkinson's Disease. In Proceedings of the The International Workshop on Innovative Simulation for Healthcare, Larnaca, Cyprus, 26-28 September 2016; pp. 51-57.

81. Schwarz, A.; Höller, M.K.; Pereira, J.; Ofner, P.; Müller-Putz, G.R. Decoding hand movements from human EEG to control a robotic arm in a simulation environment. J. Neural Eng. 2020, 17, 036010. [CrossRef]

82. Ibáñez, J.; Monge-Pereira, E.; Molina-Rueda, F.; Serrano, J.; Del Castillo, M.D.; Cuesta-Gómez, A.; Carratalá-Tejada, M.; Cano-de-la Cuerda, R.; Alguacil-Diego, I.M.; Miangolarra-Page, J.C.; et al. Low latency estimation of motor intentions to assist reaching movements along multiple sessions in chronic stroke patients: A feasibility study. Front. Neurosci. 2017, 11, 126. [CrossRef]

83. Randazzo, L.; Iturrate, I.; Perdikis, S.; Millán, J.d.R. mano: A wearable hand exoskeleton for activities of daily living and neurorehabilitation. IEEE Robot. Autom. Lett. 2017, 3, 500-507. [CrossRef]

84. Liang, H.; Zhu, C.; Iwata, Y.; Maedono, S.; Mochida, M.; Yu, H.; Yan, Y.; Duan, F. Motion estimation for the control of upper limb wearable exoskeleton robot with electroencephalography signals. In Proceedings of the 2018 IEEE International Conference on Cyborg and Bionic Systems (CBS), Shenzhen, China, 25-27 October 2018; pp. 228-233.

85. Mallikarachchi, S.; Chinthaka, D.; Sandaruwan, J.; Ruhunage, I.; Lalitharatne, T.D. Motor imagery EEG-EOG signals based Brain Machine Interface (BMI) for a Mobile Robotic Assistant (MRA). In Proceedings of the 2019 IEEE 19th International Conference on Bioinformatics and Bioengineering (BIBE), Athens, Greece, 28-30 October 2019; pp. 812-816.

86. Vourvopoulos, A.; i Badia, S.B. Motor priming in virtual reality can augment motor-imagery training efficacy in restorative brain-computer interaction: A within-subject analysis. J. Neuroeng. Rehabil. 2016, 13, 1-14. [CrossRef]

87. Gomez-Pilar, J.; Corralejo, R.; Nicolas-Alonso, L.F.; Álvarez, D.; Hornero, R. Neurofeedback training with a motor imagery-based BCI: Neurocognitive improvements and EEG changes in the elderly. Med Biol. Eng. Comput. 2016, 54, 1655-1666. [CrossRef]

88. Lim, H.; Ku, J. A brain-computer interface-based action observation game that enhances mu suppression. IEEE Trans. Neural Syst. Rehabil. Eng. 2018, 26, 2290-2296. [CrossRef]

89. Liu, D.; Chen, W.; Pei, Z.; Wang, J. A brain-controlled lower-limb exoskeleton for human gait training. Rev. Sci. Instruments 2017, 88, 104302. [CrossRef]

90. Amaral, C.; Mouga, S.; Simões, M.; Pereira, H.C.; Bernardino, I.; Quental, H.; Playle, R.; McNamara, R.; Oliveira, G.; Castelo-Branco, M. A feasibility clinical trial to improve social attention in Autistic Spectrum Disorder (ASD) using a brain computer interface. Front. Neurosci. 2018, 12, 477. [CrossRef]

91. Käthner, I.; Halder, S.; Hintermüller, C.; Espinosa, A.; Guger, C.; Miralles, F.; Vargiu, E.; Dauwalder, S.; Rafael-Palou, X.; Solà, M.; et al. A multifunctional brain-computer interface intended for home use: An evaluation with healthy participants and potential end users with dry and gel-based electrodes. Front. Neurosci. 2017, 11, 286. [CrossRef]

92. Hashimoto, Y.; Kakui, T.; Ushiba, J.; Liu, M.; Kamada, K.; Ota, T. Development of rehabilitation system with brain-computer interface for subacute stroke patients. In Proceedings of the 2018 IEEE International Conference on Systems, Man, and Cybernetics (SMC), Miyazaki, Japan, 7-10 October 2018; pp. 51-56.

93. Kawakami, M.; Fujiwara, T.; Ushiba, J.; Nishimoto, A.; Abe, K.; Honaga, K.; Nishimura, A.; Mizuno, K.; Kodama, M.; Masakado, Y.; et al. A new therapeutic application of brain-machine interface (BMI) training followed by hybrid assistive neuromuscular dynamic stimulation (HANDS) therapy for patients with severe hemiparetic stroke: A proof of concept study. Restor. Neurol. Neurosci. 2016, 34, 789-797. [CrossRef]

94. Will, M.; Peter, T.; Hanses, M.; Elkmann, N.; Rose, G.; Hinrichs, H.; Reichert, C. A robot control platform for motor impaired people. In Proceedings of the 2020 IEEE International Conference on Systems, Man, and Cybernetics (SMC), Toronto, ON, Canada, 11-14 October 2020; pp. 2025-2030. 
95. Chowdhury, A.; Meena, Y.K.; Raza, H.; Bhushan, B.; Uttam, A.K.; Pandey, N.; Hashmi, A.A.; Bajpai, A.; Dutta, A.; Prasad, G. Active physical practice followed by mental practice using BCI-driven hand exoskeleton: A pilot trial for clinical effectiveness and usability. IEEE J. Biomed. Health Inform. 2018, 22, 1786-1795. [CrossRef]

96. Aliakbaryhosseinabadi, S.; Mrachacz-Kersting, N. Adaptive brain-computer interface with attention alterations in patients with amyotrophic lateral sclerosis. In Proceedings of the 2020 42nd Annual International Conference of the IEEE Engineering in Medicine \& Biology Society (EMBC), Montreal, QC, Canada, 20-24 July 2020; pp. 3188-3191.

97. Nierula, B.; Spanlang, B.; Martini, M.; Borrell, M.; Nikulin, V.V.; Sanchez-Vives, M.V. Agency and responsibility over virtual movements controlled through different paradigms of brain- computer interface. J. Physiol. 2019, 599, 2419-2434. [CrossRef]

98. Martínez-Cagigal, V.; Gomez-Pilar, J.; Alvarez, D.; Hornero, R. An asynchronous P300-based brain-computer interface web browser for severely disabled people. IEEE Trans. Neural Syst. Rehabil. Eng. 2016, 25, 1332-1342. [CrossRef]

99. Shahriari, Y.; Vaughan, T.M.; McCane, L.; Allison, B.Z.; Wolpaw, J.R.; Krusienski, D.J. An exploration of BCI performance variations in people with amyotrophic lateral sclerosis using longitudinal EEG data. J. Neural Eng. 2019, 16, 056031. [CrossRef]

100. Hernández-Rojas, L.G.; Montoya, O.M.; Antelis, J.M. Anticipatory detection of self-paced rehabilitative movements in the same upper limb from EEG signals. IEEE Access 2020, 8, 119728-119743. [CrossRef]

101. Sánchez, B.C.C.; Carvajal, L.C.L.; Quitian, F.L.G.T.; López, J.M.L. BCI for meal assistance device. In Latin American Conference on Biomedical Engineering; Springer: Berlin/Heidelberg, Germany, 2019; pp. 1117-1121.

102. McFarland, D.; Norman, S.; Sarnacki, W.; Wolbrecht, E.; Reinkensmeyer, D.; Wolpaw, J. BCI-based sensorimotor rhythm training can affect individuated finger movements. Brain-Comput. Interfaces 2020, 7, 38-46. [CrossRef]

103. Mattia, D.; Pichiorri, F.; Colamarino, E.; Masciullo, M.; Morone, G.; Toppi, J.; Pisotta, I.; Tamburella, F.; Lorusso, M.; Paolucci, S.; et al. The Promotoer, a brain-computer interface-assisted intervention to promote upper limb functional motor recovery after stroke: A study protocol for a randomized controlled trial to test early and long-term efficacy and to identify determinants of response. BMC Neurol. 2020, 20,1-13. [CrossRef] [PubMed]

104. Karácsony, T.; Hansen, J.P.; Iversen, H.K.; Puthusserypady, S. Brain computer interface for neuro-rehabilitation with deep learning classification and virtual reality feedback. In Proceedings of the 10th Augmented Human International Conference 2019, New York, NY, USA, 11-12 March 2019; pp. 1-8.

105. Di Flumeri, G.; De Crescenzio, F.; Berberian, B.; Ohneiser, O.; Kramer, J.; Aricò, P.; Borghini, G.; Babiloni, F.; Bagassi, S.; Piastra, S. Brain-computer interface-based adaptive automation to prevent out-of-the-loop phenomenon in air traffic controllers dealing with highly automated systems. Front. Hum. Neurosci. 2019, 13, 296. [CrossRef]

106. Irimia, D.C.; Cho, W.; Ortner, R.; Allison, B.Z.; Ignat, B.E.; Edlinger, G.; Guger, C. Brain-computer interfaces with multi-sensory feedback for stroke rehabilitation: A case study. Artif. Organs 2017, 41, E178-E184. [CrossRef]

107. Schildt, C.J.; Thomas, S.H.; Powell, E.S.; Sawaki, L.; Sunderam, S. Closed-loop afferent electrical stimulation for recovery of hand function in individuals with motor incomplete spinal injury: Early clinical results. In Proceedings of the 201638 th Annual International Conference of the IEEE Engineering in Medicine and Biology Society (EMBC), Orlando, FL, USA, 16-20 August 2016; pp. 1552-1555.

108. Resquín, F.; Ibáñez, J.; Gonzalez-Vargas, J.; Brunetti, F.; Dimbwadyo, I.; Alves, S.; Carrasco, L.; Torres, L.; Pons, J.L. Combining a hybrid robotic system with a bain-machine interface for the rehabilitation of reaching movements: A case study with a stroke patient. In Proceedings of the 2016 38th Annual International Conference of the IEEE Engineering in Medicine and Biology Society (EMBC), Orlando, FL, USA, 16-20 August 2016; pp. 6381-6384.

109. Suwannarat, A.; Pan-Ngum, S.; Israsena, P. Comparison of EEG measurement of upper limb movement in motor imagery training system. Biomed. Eng. Online 2018, 17, 1-22. [CrossRef]

110. Liang, H.; Zhu, C.; Tian, Y.; Iwata, Y.; Maedono, S.; Yu, H.; Yan, Y.; Duan, F. Construction of power assistive system for the control of upper limb wearable exoskeleton robot with electroencephalography signals. In Proceedings of the 2017 IEEE International Conference on Cyborg and Bionic Systems (CBS), Beijing, China, 17-19 October 2017; pp. 165-168.

111. Chowdhury, A.; Raza, H.; Dutta, A.; Prasad, G. EEG-EMG based hybrid brain computer interface for triggering hand exoskeleton for neuro-rehabilitation. In Proceedings of the Advances in Robotics, New Delhi, India, 28 June-2 July 201 ; pp. 1-6.

112. Scherer, R.; Schwarz, A.; Müller-Putz, G.R.; Pammer-Schindler, V.; Garcia, M.L. Game-based BCI training: Interactive design for individuals with cerebral palsy. In Proceedings of the 2015 IEEE International Conference on Systems, Man, and Cybernetics, Hong Kong, China, 9-12 October 2015; pp. 3175-3180.

113. Carrere, L.; Tabernig, C. Motor imagery BCI system with visual feedback: Design and preliminary evaluation. In Proceedings of the VII Latin American Congress on Biomedical Engineering CLAIB 2016, Bucaramanga, Santander, Colombia, 26-28 October 2016; Springer: Berlin/Heidelberg, Germany, 2017; pp. 709-712.

114. Martínez-Cagigal, V.; Santamaría-Vázquez, E.; Gomez-Pilar, J.; Hornero, R. Towards an accessible use of smartphone-based social networks through brain-computer interfaces. Expert Syst. Appl. 2019, 120, 155-166. [CrossRef]

115. Kobayashi, N.; Sato, K. P300-based control for assistive robot for habitat. In Proceedings of the 2017 IEEE 6th Global Conference on Consumer Electronics (GCCE), Nagoya, Japan, 24-27 October 2017; pp. 1-5.

116. Zhang, S.; Yoshida, W.; Mano, H.; Yanagisawa, T.; Mancini, F.; Shibata, K.; Kawato, M.; Seymour, B. Pain control by co-adaptive learning in a brain-machine interface. Curr. Biol. 2020, 30, 3935-3944. [CrossRef] 
117. Pacheco, K.; Acuna, K.; Carranza, E.; Achanccaray, D.; Andreu-Perez, J. Performance predictors of motor imagery brain-computer interface based on spatial abilities for upper limb rehabilitation. In Proceedings of the 2017 39th Annual International Conference of the IEEE Engineering in Medicine and Biology Society (EMBC), Jeju, Korea, 11-15 July 2017; pp. 1014-1017.

118. Hashimoto, Y.; Kakui, T.; Ushiba, J.; Liu, M.; Kamada, K.; Ota, T. Portable rehabilitation system with brain-computer interface for inpatients with acute and subacute stroke: A feasibility study. Assist. Technol. 2020. [CrossRef]

119. Elvira, M.; Iáñez, E.; Quiles, V.; Ortiz, M.; Azorín, J.M. Pseudo-online BMI based on EEG to detect the appearance of sudden obstacles during walking. Sensors 2019, 19, 5444. [CrossRef]

120. Aliakbaryhosseinabadi, S.; Farina, D.; Mrachacz-Kersting, N. Real-time neurofeedback is effective in reducing diversion of attention from a motor task in healthy individuals and patients with amyotrophic lateral sclerosis. J. Neural Eng. 2020, $17,036017$. [CrossRef]

121. Osuagwu, B.C.; Wallace, L.; Fraser, M.; Vuckovic, A. Rehabilitation of hand in subacute tetraplegic patients based on brain computer interface and functional electrical stimulation: A randomised pilot study. J. Neural Eng. 2016, 13, 065002. [CrossRef]

122. Alimardani, M.; Kemmeren, L.; Okumura, K.; Hiraki, K. Robot-assisted mindfulness practice: Analysis of neurophysiological responses and affective state change. In Proceedings of the 2020 29th IEEE International Conference on Robot and Human Interactive Communication (RO-MAN), Naples, Italy, 31 August-4 September 2020; pp. 683-689.

123. Mezzina, G.; De Venuto, D. Semi-autonomous personal care robots interface driven by EEG signals digitization. In Proceedings of the 2020 Design, Automation \& Test in Europe Conference \& Exhibition (DATE), Grenoble, France, 9-13 March 2020; pp. 264-269.

124. Jebri, A.; Madani, T.; Djouani, K. Neural Adaptive Integral-Sliding-Mode Controller with a SSVEP-based BCI for Exoskeletons. In Proceedings of the 2019 19th International Conference on Advanced Robotics (ICAR), Belo Horizonte, Brazil, 2-6 December 2019; pp. 87-92.

125. Yu, G.; Wang, J.; Chen, W.; Zhang, J. EEG-based brain-controlled lower extremity exoskeleton rehabilitation robot. In Proceedings of the 2017 IEEE International Conference on Cybernetics and Intelligent Systems (CIS) and IEEE Conference on Robotics, Automation and Mechatronics (RAM), Ningbo, China, 19-21 November 2017; pp. 763-767.

126. Xu, R.; Dosen, S.; Jiang, N.; Yao, L.; Farooq, A.; Jochumsen, M.; Mrachacz-Kersting, N.; Dremstrup, K.; Farina, D. Continuous 2D control via state-machine triggered by endogenous sensory discrimination and a fast brain switch. J. Neural Eng. 2019, 16, 056001 [CrossRef]

127. Irimia, D.C.; Poboroniuc, M.S.; Serea, F.; Baciu, A.; Olaru, R. Controlling a FES-EXOSKELETON rehabilitation system by means of brain-computer interface. In Proceedings of the 2016 International Conference and Exposition on Electrical and Power Engineering (EPE), Iasi, Romania, 20-22 October 2016; pp. 352-355.

128. Norman, S.; McFarland, D.; Miner, A.; Cramer, S.; Wolbrecht, E.; Wolpaw, J.; Reinkensmeyer, D. Controlling pre-movement sensorimotor rhythm can improve finger extension after stroke. J. Neural Eng. 2018, 15, 056026. [CrossRef] [PubMed]

129. Nataraj, S.K.; Paulraj, M.; Yaacob, S.B.; Adom, A.H.B. Thought-actuated wheelchair navigation with communication assistance using statistical cross-correlation-based features and extreme learning machine. J. Med. Signals Sens. 2020, 10, 228.

130. Hortal, E.; Úbeda, A.; Iáñez, E.; Azorín, J.M.; Fernández, E. EEG-based detection of starting and stopping during gait cycle. Int. J. Neural Syst. 2016, 26, 1650029. [CrossRef]

131. Marghi, Y.M.; Farjadian, A.B.; Yen, S.C.; Erdogmus, D. EEG-guided robotic mirror therapy system for lower limb rehabilitation. In Proceedings of the 2017 39th Annual International Conference of the IEEE Engineering in Medicine and Biology Society (EMBC), Jeju, Korea, 11-15 July 2017; pp. 1917-1921.

132. Kumar, A.; Fang, Q.; Fu, J.; Pirogova, E.; Gu, X. Error-related neural responses recorded by electroencephalography during post-stroke rehabilitation movements. Front. Neurorobotics 2019, 13, 107. [CrossRef] [PubMed]

133. Delijorge, J.; Mendoza-Montoya, O.; Gordillo, J.L.; Caraza, R.; Martinez, H.R.; Antelis, J.M. Evaluation of a P300-based brain-machine interface for a robotic hand-orthosis control. Front. Neurosci. 2020, 14, 589659. [CrossRef]

134. Alchalabi, A.E.; Shirmohammadi, S.; Eddin, A.N.; Elsharnouby, M. FOCUS: Detecting ADHD patients by an EEG-based serious game. IEEE Trans. Instrum. Meas. 2018, 67, 1512-1520. [CrossRef]

135. Braun, J.F.; Díez-Valencia, G.; Ehrlich, S.K.; Lanillos, P.; Cheng, G. A prototype of a P300 based brain-robot interface to enable multi-modal interaction for patients with limited mobility. In Proceedings of the 2019 IEEE International Conference on Cyborg and Bionic Systems (CBS), Munich, Germany, 18-20 September 2019; pp. 78-84.

136. Romo Badillo, M.; Toriz Palacios, A.; Nuño de la Parra, P. Brain-Computer Interface (BCI) Development for Motor Disabled People Integration in the Manufacturing SME. Comput. Y Sist. 2018, 22, 505-520 [CrossRef]

137. Salisbury, D.B.; Parsons, T.D.; Monden, K.R.; Trost, Z.; Driver, S.J. Brain-computer interface for individuals after spinal cord injury. Rehabil. Psychol. 2016, 61, 435. [CrossRef] [PubMed]

138. Vinoj, P.; Jacob, S.; Menon, V.G.; Rajesh, S.; Khosravi, M.R. Brain-controlled adaptive lower limb exoskeleton for rehabilitation of post-stroke paralyzed. IEEE Access 2019, 7, 132628-132648. [CrossRef]

139. Barresi, G.; Olivieri, E.; Caldwell, D.G.; Mattos, L.S. Brain-controlled AR feedback design for user's training in surgical HRI. In Proceedings of the 2015 IEEE International Conference on Systems, Man, and Cybernetics, Hong Kong, China, 9-12 October 2015; pp. 1116-1121.

140. Zeng, H.; Wang, Y.; Wu, C.; Song, A.; Liu, J.; Ji, P.; Xu, B.; Zhu, L.; Li, H.; Wen, P. Closed-loop hybrid gaze brain-machine interface based robotic arm control with augmented reality feedback. Front. Neurorobotics 2017, 11, 60. [CrossRef] 
141. Manolova, A.; Tsenov, G.; Lazarova, V.; Neshov, N. Combined EEG and EMG fatigue measurement framework with application to hybrid brain-computer interface. In Proceedings of the 2016 IEEE International Black Sea Conference on Communications and Networking (BlackSeaCom), Varna, Bulgaria, 6-9 June 2016; pp. 1-5.

142. Athanasiou, A.; Arfaras, G.; Xygonakis, I.; Kartsidis, P.; Pandria, N.; Kavazidi, K.R.; Astaras, A.; Foroglou, N.; Polyzoidis, K.; Bamidis, P.D. Commercial BCI Control and functional brain networks in spinal cord injury: A proof-of-concept. In Proceedings of the 2017 IEEE 30th International Symposium on Computer-Based Medical Systems (CBMS), Thessaloniki, Greece, 22-24 June 2017; pp. 262-267.

143. Wang, Y.; Xu, G.; Song, A.; Xu, B.; Li, H.; Hu, C.; Zeng, H. Continuous shared control for robotic arm reaching driven by a hybrid gaze-brain machine interface. In Proceedings of the 2018 IEEE/RSJ International Conference on Intelligent Robots and Systems (IROS), Madrid, Spain, 1-5 October 2018; pp. 4462-4467.

144. Naijian, C.; Xiangdong, H.; Yantao, W.; Xinglai, C.; Hui, C. Coordination control strategy between human vision and wheelchair manipulator based on BCI. In Proceedings of the 2016 IEEE 11th Conference on Industrial Electronics and Applications (ICIEA), Hefei, China, 5-7 June 2016; pp. 1872-1875.

145. Yu, Y.C.; Smith, B.; Goreshnik, A.; Gabel, L. Design of an affordable brain-computer interface for robot navigation. In Proceedings of the 2019 14th IEEE Conference on Industrial Electronics and Applications (ICIEA), Xi'an, China, 19-21 June 2019 ; pp. 787-792.

146. Huang, X.; Xue, X.; Yuan, Z. A simulation platform for the Brain-Computer Interface (BCI) based smart wheelchair. In International Conference on Artificial Intelligence and Security; Springer: Berlin/Heidelberg, Germany, 2020; pp. 257-266.

147. Von Gwayneth, B.A.; Dungca, C.J.N.; Lazam, S.A.; Pereira, M.N.L.; Tan, J.R.O.; Prado, S.V. Development of an EEG-based motor imagery brain-computer interface system for lower limb assistive technologies. In Proceedings of the 2018 IEEE 10 th International Conference on Humanoid, Nanotechnology, Information Technology, Communication and Control, Environment and Management (HNICEM), Baguio City, Philippines, 29 November-2 December 2018; pp. 1-6.

148. Bousseta, R.; El Ouakouak, I.; Gharbi, M.; Regragui, F. EEG based brain computer interface for controlling a robot arm movement through thought. Irbm 2018, 39, 129-135. [CrossRef]

149. Osama, M.; Aslam, M.H. Emotiv EPOC+ fed electrical muscle stimulation system; an inexpensive brain-computer interface for rehabilitation of neuro-muscular disorders. JPMA 2020, 2019, 526-530

150. Taherian, S.; Selitskiy, D.; Pau, J.; Davies, T.C.; Owens, R.G. Training to use a commercial brain-computer interface as access technology: A case study. Disabil. Rehabil. Assist. Technol. 2016, 11, 345-350. [CrossRef]

151. Bi, Q.; Yang, C.; Yang, W.; Fan, J.; Wang, H. Hand Exoskeleton Control for Cerebrum Plasticity Training Based on Brain-Computer Interface. In Wearable Sensors and Robots; Springer: Berlin/Heidelberg, Germany, 2017; pp. 395-410.

152. Achic, F.; Montero, J.; Penaloza, C.; Cuellar, F. Hybrid BCI system to operate an electric wheelchair and a robotic arm for navigation and manipulation tasks. In Proceedings of the 2016 IEEE workshop on advanced robotics and its social impacts (ARSO), Shanghai, China, 8-10 July 2016; pp. 249-254.

153. Alchalcabi, A.E.; Eddin, A.N.; Shirmohammadi, S. More attention, less deficit: Wearable EEG-based serious game for focus improvement. In Proceedings of the 2017 IEEE 5th International Conference on Serious Games and Applications for Health (SeGAH), Perth, Australia, 2-4 April 2017; pp. 1-8.

154. Kumar, P.; Saini, R.; Sahu, P.K.; Roy, P.P.; Dogra, D.P.; Balasubramanian, R. Neuro-phone: An assistive framework to operate Smartphone using EEG signals. In Proceedings of the 2017 IEEE Region 10 Symposium (TENSYMP), Cochin, India, 14-16 July 2017; pp. 1-5.

155. Abiri, R.; Borhani, S.; Zhao, X.; Jiang, Y. Real-time brain machine interaction via social robot gesture control. In Proceedings of the Dynamic Systems and Control Conference, Tysons Corner, VA, USA, 11-13 October 2017.

156. Chu, Y.; Zhao, X.; Zou, Y.; Xu, W.; Zhao, Y. Robot-assisted rehabilitation system based on SSVEP brain-computer interface for upper extremity. In Proceedings of the 2018 IEEE International Conference on Robotics and Biomimetics (ROBIO), Kuala Lumpur, Malaysia, 12-15 December 2018; pp. 1098-1103.

157. Staffa, M.; Giordano, M.; Ficuciello, F. A WiSARD network approach for a BCI-based robotic prosthetic control. Int. J. Soc. Robot. 2020, 12, 749-764. [CrossRef]

158. Schiatti, L.; Tessadori, J.; Barresi, G.; Mattos, L.S.; Ajoudani, A. Soft brain-machine interfaces for assistive robotics: A novel control approach. In Proceedings of the 2017 International Conference on Rehabilitation Robotics (ICORR), London, UK, 17-20 July 2017; pp. 863-869.

159. Zhao, X.; Chu, Y.; Han, J.; Zhang, Z. SSVEP-based brain-computer interface controlled functional electrical stimulation system for upper extremity rehabilitation. IEEE Trans. Syst. Man, Cybern. Syst. 2016, 46, 947-956. [CrossRef]

160. Li, Y.; Zhou, G.; Graham, D.; Holtzhauer, A. Towards an EEG-based brain-computer interface for online robot control. Multimed. Tools Appl. 2016, 75, 7999-8017. [CrossRef]

161. Ihsan, I.A.; Tomari, R.; Zakaria, W.N.W.; Othman, N. Alternative input medium development for wheelchair user with severe spinal cord injury. AIP Conf. Proc. 2017, 1883, 020032.

162. Ramirez, R. An Expressive Brain-Computer Music Interface for Musical Neurofeedback; University of Michigan Library: Ann Arbor, MI, USA, 2018.

163. Ali, H.A.; Goga, N.; Marian, C.V.; Ali, L.A. An Investigation of Mind-Controlled Prosthetic Arm Intelligent System. ELearning Softw. Educ. 2020, 2, 17-26. 
164. Al-Hudhud, G.; Alqahtani, L.; Albaity, H.; Alsaeed, D.; Al-Turaiki, I. Analyzing passive BCI signals to control adaptive automation devices. Sensors 2019, 19, 3042. [CrossRef]

165. Taherian, S.; Selitskiy, D.; Pau, J.; Claire Davies, T. Are we there yet? Evaluating commercial grade brain-computer interface for control of computer applications by individuals with cerebral palsy. Disabil. Rehabil. Assist. Technol. 2017, 12, 165-174. [CrossRef]

166. Sreeja, S.; Joshi, V.; Samima, S.; Saha, A.; Rabha, J.; Cheema, B.S.; Samanta, D.; Mitra, P. BCI augmented text entry mechanism for people with special needs. In International Conference on Intelligent Human Computer Interaction; Springer: Berlin/Heidelberg, Germany, 2016; pp. 81-93.

167. Qiu, S.; Li, Z.; He, W.; Zhang, L.; Yang, C.; Su, C.Y. Brain-machine interface and visual compressive sensing-based teleoperation control of an exoskeleton robot. IEEE Trans. Fuzzy Syst. 2016, 25, 58-69. [CrossRef]

168. Khan, A.; Chen, C.; Yuan, K.; Wang, X.; Mehra, P.; Liu, Y.; Tong, K.Y. Changes in electroencephalography complexity and functional magnetic resonance imaging connectivity following robotic hand training in chronic stroke. Top. Stroke Rehabil. 2020, 28, 276-288. [CrossRef] [PubMed]

169. Li, Z.; He, W.; Yang, C.; Qiu, S.; Zhang, L.; Su, C.Y. Teleoperation control of an exoskeleton robot using brain machine interface and visual compressive sensing. In Proceedings of the 2016 12th World Congress on Intelligent Control and Automation (WCICA), Guilin, China, 12-15 June 2016; pp. 1550-1555.

170. Chen, S.C.; Hsu, C.H.; Kuo, H.C.; Zaeni, I.A. The BCI control applied to the interactive autonomous robot with the function of meal assistance. In Proceedings of the 3rd International Conference on Intelligent Technologies and Engineering Systems (ICITES2014); Springer: Berlin/Heidelberg, Germany, 2016; pp. 475-483.

171. Xiao, J.; Pan, J.; He, Y.; Xie, Q.; Yu, T.; Huang, H.; Lv, W.; Zhang, J.; Yu, R.; Li, Y. Visual fixation assessment in patients with disorders of consciousness based on brain-computer interface. Neurosci. Bull. 2018, 34, 679-690. [CrossRef]

172. Deng, X.; Yu, Z.L.; Lin, C.; Gu, Z.; Li, Y. A bayesian shared control approach for wheelchair robot with brain machine interface. IEEE Trans. Neural Syst. Rehabil. Eng. 2019, 28, 328-338. [CrossRef] [PubMed]

173. Xiao, J.; Lin, Q.; Yu, T.; Xie, Q.; Yu, R.; Li, Y. A BCI system for assisting visual fixation assessment in behavioral evaluation of patients with disorders of consciousness. In Proceedings of the 2017 8th International IEEE/EMBS Conference on Neural Engineering (NER), Shanghai, China, 25-28 May 2017; pp. 399-402.

174. Wang, F.; He, Y.; Qu, J.; Cao, Y.; Liu, Y.; Li, F.; Yu, Z.; Yu, R.; Li, Y. A Brain-Computer Interface Based on Three-Dimensional Stereo Stimuli for Assisting Clinical Object Recognition Assessment in Patients With Disorders of Consciousness. IEEE Trans. Neural Syst. Rehabil. Eng. 2019, 27, 507-513. [CrossRef] [PubMed]

175. Wang, K.; Wang, Z.; Guo, Y.; He, F.; Qi, H.; Xu, M.; Ming, D. A brain-computer interface driven by imagining different force loads on a single hand: An online feasibility study. J. Neuroeng. Rehabil. 2017, 14, 1-10. [CrossRef] [PubMed]

176. Tung, S.W.; Guan, C.; Ang, K.K.; Phua, K.S.; Wang, C.; Kuah, C.W.K.; Chua, K.S.G.; Ng, Y.S.; Zhao, L.; Chew, E. A measurement of motor recovery for motor imagery-based BCI using EEG coherence analysis. In Proceedings of the 201510 th International Conference on Information, Communications and Signal Processing (ICICS), Singapore, 2-4 December 2015; pp. 1-5.

177. Lin, X.; Malik, W.Q.; Zhang, S. A novel hybrid BCI web browser based on SSVEP and eye-Tracking. In Proceedings of the 2019 IEEE Biomedical Circuits and Systems Conference (BioCAS), Nara, Japan, 17-19 October 2019; pp. 1-4.

178. Xiao, J.; Xie, Q.; He, Y.; Yu, T.; Lu, S.; Huang, N.; Yu, R.; Li, Y. An auditory BCI system for assisting CRS-R behavioral assessment in patients with disorders of consciousness. Sci. Rep. 2016, 6, 1-13. [CrossRef]

179. Friesen, C.L.; Bardouille, T.; Neyedli, H.F.; Boe, S.G. Combined action observation and motor imagery neurofeedback for modulation of brain activity. Front. Hum. Neurosci. 2017, 10, 692. [CrossRef]

180. Zhang, J.; Wang, B.; Zhang, C.; Xiao, Y.; Wang, M.Y. An EEG/EMG/EOG-based multimodal human-machine interface to real-time control of a soft robot hand. Front. Neurorobotics 2019, 13, 7. [CrossRef] [PubMed]

181. Huang, Q.; Zhang, Z.; Yu, T.; He, S.; Li, Y. An EEG-/EOG-based hybrid brain-computer interface: Application on controlling an integrated wheelchair robotic arm system. Front. Neurosci. 2019, 13, 1243. [CrossRef] [PubMed]

182. Xiao, J.; Xie, Q.; Lin, Q.; Yu, T.; Yu, R.; Li, Y. Assessment of visual pursuit in patients with disorders of consciousness based on a brain-computer interface. IEEE Trans. Neural Syst. Rehabil. Eng. 2018, 26, 1141-1151. [CrossRef]

183. Liu, Y.T.; Lin, Y.Y.; Wu, S.L.; Chuang, C.H.; Lin, C.T. Brain dynamics in predicting driving fatigue using a recurrent self-evolving fuzzy neural network. IEEE Trans. Neural Netw. Learn. Syst. 2015, 27, 347-360. [CrossRef]

184. Marquez-Chin, C.; Marquis, A.; Popovic, M.R. EEG-triggered functional electrical stimulation therapy for restoring upper limb function in chronic stroke with severe hemiplegia. Case Rep. Neurol. Med. 2016, 2016, 9146213. [CrossRef]

185. Jochumsen, M.; Navid, M.S.; Rashid, U.; Haavik, H.; Niazi, I.K. EMG-versus EEG-triggered electrical stimulation for inducing corticospinal plasticity. IEEE Trans. Neural Syst. Rehabil. Eng. 2019, 27, 1901-1908. [CrossRef]

186. Li, Z.; Yuan, Y.; Luo, L.; Su, W.; Zhao, K.; Xu, C.; Huang, J.; Pi, M. Hybrid brain/muscle signals powered wearable walking exoskeleton enhancing motor ability in climbing stairs activity. IEEE Trans. Med. Robot. Bionics 2019, 1, 218-227. [CrossRef]

187. Butt, M.; Naghdy, G.; Naghdy, F.; Murray, G.; Du, H. Investigating electrode sites for intention detection during robot based hand movement using EEG-BCI system. In Proceedings of the 2018 IEEE 18th International Conference on Bioinformatics and Bioengineering (BIBE), Taichung, Taiwan, 29-31 October 2018; pp. 177-180.

188. Butt, M.; Naghdy, G.; Naghdy, F.; Murray, G.; Du, H. Investigating the detection of intention signal during different exercise protocols in robot-assisted hand movement of stroke patients and healthy subjects using EEG-BCI system. Adv. Sci. Technol. Eng. Syst. J. 2019, 4, 300-307. [CrossRef] 
189. Pan, J.; Xie, Q.; Qin, P.; Chen, Y.; He, Y.; Huang, H.; Wang, F.; Ni, X.; Cichocki, A.; Yu, R.; et al. Prognosis for patients with cognitive motor dissociation identified by brain-computer interface. Brain 2020, 143, 1177-1189. [CrossRef]

190. Deng, X.; Yu, Z.L.; Lin, C.; Gu, Z.; Li, Y. Self-adaptive shared control with brain state evaluation network for human-wheelchair cooperation. J. Neural Eng. 2020, 17, 045005. [CrossRef] [PubMed]

191. Kuo, C.H.; Chen, H.H.; Chou, H.C.; Chen, P.N.; Kuo, Y.C. Wireless stimulus-on-device design for novel P300 hybrid braincomputer interface applications. Comput. Intell. Neurosci. 2018, 2018, 2301804. [CrossRef] [PubMed]

192. Tang, J.; Zhou, Z.; Yu, Y. A hybrid computer interface for robot arm control. In Proceedings of the 2016 8th International Conference on Information Technology in Medicine and Education (ITME), Fuzhou, China, 23-25 December 2016; pp. 365-369.

193. Luu, T.P.; He, Y.; Brown, S.; Nakagome, S.; Contreras-Vidal, J.L. Gait adaptation to visual kinematic perturbations using a real-time closed-loop brain-computer interface to a virtual reality avatar. J. Neural Eng. 2016, 13, 036006. [CrossRef] [PubMed]

194. Sullivan, J.L.; Bhagat, N.A.; Yozbatiran, N.; Paranjape, R.; Losey, C.G.; Grossman, R.G.; Contreras-Vidal, J.L.; Francisco, G.E.; O'Malley, M.K. Improving robotic stroke rehabilitation by incorporating neural intent detection: Preliminary results from a clinical trial. In Proceedings of the 2017 International Conference on Rehabilitation Robotics (ICORR), London, UK, 17-20 July 2017; pp. 122-127.

195. Song, M.; Kim, J. Motor imagery enhancement paradigm using moving rubber hand illusion system. In Proceedings of the 2017 39th Annual International Conference of the IEEE Engineering in Medicine and Biology Society (EMBC), Jeju, Korea, 11-15 July 2017; pp. 1146-1149.

196. Mastakouri, A.A.; Weichwald, S.; Özdenizci, O.; Meyer, T.; Schölkopf, B.; Grosse-Wentrup, M. Personalized brain-computer interface models for motor rehabilitation. In Proceedings of the 2017 IEEE International Conference on Systems, Man, and Cybernetics (SMC), Banff, AB, Canada, 5-8 October 2017; pp. 3024-3029.

197. Ortiz, M.; Ferrero, L.; Iáñez, E.; Azorín, J.M.; Contreras-Vidal, J.L. Sensory integration in human movement: A new brain-machine interface based on gamma band and attention level for controlling a lower-limb exoskeleton. Front. Bioeng. Biotechnol. 2020, 8. [CrossRef] [PubMed]

198. Tang, J.; Liu, Y.; Hu, D.; Zhou, Z. Towards BCI-actuated smart wheelchair system. Biomed. Eng. Online 2018, 17, 1-22. [CrossRef] [PubMed]

199. Lóopez-Larraz, E.; Birbaumer, N.; Ramos-Murguialday, A. A hybrid EEG-EMG BMI improves the detection of movement intention in cortical stroke patients with complete hand paralysis. In Proceedings of the 2018 40th Annual International Conference of the IEEE Engineering in Medicine and Biology Society (EMBC), Honolulu, HI, USA, 18-21 July 2018; pp. 2000-2003.

200. Song, M.; Kim, J. A paradigm to enhance motor imagery using rubber hand illusion induced by visuo-tactile stimulus. IEEE Trans. Neural Syst. Rehabil. Eng. 2019, 27, 477-486. [CrossRef]

201. da Silva-Sauer, L.; Valero-Aguayo, L.; Velasco-Álvarez, F.; Fernández-Rodríguez, Á.; Ron-Angevin, R. A Shaping Procedure to Modulate Two Cognitive Tasks to Improve a Sensorimotor Rhythm-Based Brain-Computer Interface System. Span. J. Psychol. 2018, 21. [CrossRef] [PubMed]

202. Wang, W.; Yang, B.; Guan, C.; Li, B. A VR combined with MI-BCI application for upper limb rehabilitation of stroke. In Proceedings of the 2019 IEEE MTT-S International Microwave Biomedical Conference (IMBioC), Nanjing, China, 6-8 May 2019; Volume 1, pp. 1-4.

203. Roy, G.; Nirola, D.; Bhaumik, S. An approach towards development of brain controlled lower limb exoskeleton for mobility regeneration. In Proceedings of the 2019 IEEE Region 10 Symposium (TENSYMP), Kolkata, India, 7-9 June 2019; pp. 385-390.

204. Antelis, J.M.; Montesano, L.; Ramos-Murguialday, A.; Birbaumer, N.; Minguez, J. Decoding upper limb movement attempt from EEG measurements of the contralesional motor cortex in chronic stroke patients. IEEE Trans. Biomed. Eng. 2016, 64, 99-111. [CrossRef]

205. Bhagat, N.A.; Venkatakrishnan, A.; Abibullaev, B.; Artz, E.J.; Yozbatiran, N.; Blank, A.A.; French, J.; Karmonik, C.; Grossman, R.G.; O'Malley, M.K.; et al. Design and optimization of an EEG-based brain machine interface (BMI) to an upper-limb exoskeleton for stroke survivors. Front. Neurosci. 2016, 10, 122. [CrossRef]

206. Luu, T.P.; He, Y.; Nakagome, S.; Contreras-Vidal, J.L. EEG-based brain-computer interface to a virtual walking avatar engages cortical adaptation. In Proceedings of the 2017 IEEE International Conference on Systems, Man, and Cybernetics (SMC), Banff, AB, Canada, 5-8 October 2017; pp. 3054-3057.

207. Uma, M.; Prabhu, S. A feasibility study of BCI based FES model for differently abled people. In IOP Conference Series: Materials Science and Engineering; IOP Publishing: Bristol, UK, 2018; Volume 402, p. 12009.

208. Narayanan, S.; Divya, K. A Sensor based mechanism for controlling mobile robots with ZigBee. In Computational Intelligence in Data Mining_Volume 2; Springer: Berlin/Heidelberg, Germany, 2016; pp. 1-12.

209. Contreras-Castañeda, M.A.; Holgado-Terriza, J.A.; Pomboza-Junez, G.; Paderewski-Rodríguez, P.; Gutiérrez-Vela, F.L. Smart Home: Multimodal Interaction for Control of Home Devices. In Proceedings of the International Conference on Human Computer Interaction 2019, Donostia Gipuzkoa, Spain, 25-28 June 201 ; pp. 1-8.

210. Shukla, A.K. The illusive man. In Proceedings of the 2016 International Conference on Systems in Medicine and Biology (ICSMB), Kharagpur, India, 4-7 January 2016; pp. 119-123.

211. Pinheiro, O.R.; Alves, L.R.; Romero, M.; de Souza, J.R. Wheelchair simulator game for training people with severe disabilities. In Proceedings of the 2016 1st International Conference on Technology and Innovation in Sports, Health and Wellbeing (TISHW), Vila Real, Portugal, 1-3 December 2016; pp. 1-8. 
212. Raj, R.; Deb, S.; Bhattacharya, P. Brain computer interfaced single key omni directional pointing and command system: A screen pointing interface for differently-abled person. Procedia Comput. Sci. 2018, 133, 161-168. [CrossRef]

213. Stephygraph, L.R.; Arunkumar, N. Brain-actuated wireless mobile robot control through an adaptive human-machine interface. In Proceedings of the International Conference on Soft Computing Systems; Springer: Berlin/Heidelberg, Germany, 2016 ; pp. 537-549.

214. Permana, K.; Wijaya, S.; Prajitno, P. Controlled wheelchair based on brain computer interface using Neurosky Mindwave Mobile 2. AIP Confe. Proc. 2019, 2168, 020022.

215. Xin, L.; Gao, S.; Tang, J.; Xu, X. Design of a Brain Controlled Wheelchair. In Proceedings of the 2018 IEEE 4 th International Conference on Control Science and Systems Engineering (ICCSSE), Wuhan, China, 21-23 August 2018; pp. 112-116.

216. Dev, A.; Rahman, M.A.; Mamun, N. Design of an EEG-based brain controlled wheelchair for quadriplegic patients. In Proceedings of the 2018 3rd International Conference for Convergence in Technology (I2CT), Pune, India, 6-8 April 2018; pp. 1-5.

217. Blandón, D.Z.; Muñoz, J.E.; Lopez, D.S.; Gallo, O.H. Influence of a BCI neurofeedback videogame in children with ADHD. Quantifying the brain activity through an EEG signal processing dedicated toolbox. In Proceedings of the 2016 IEEE 11th Colombian Computing Conference (CCC), Popayan, Colombia, 27-30 September 2016; pp. 1-8.

218. Waheed, S.A.; Khader, P.S.A. IoT based approach for detection of dominating emotions in persons who stutter. In Proceedings of the 2020 Fourth International Conference on I-SMAC (IoT in Social, Mobile, Analytics and Cloud) (I-SMAC), Palladam, India, 7-9 October 2020; pp. 14-18.

219. Punsawad, Y.; Ngamrussameewong, S.; Wongsawat, Y. On the development of BCI and its neurofeedback training system for assistive communication device in persons with severe disability. In Proceedings of the 2016 Asia-Pacific Signal and Information Processing Association Annual Summit and Conference (APSIPA), Jeju, Korea, 13-16 December 2016; pp. 1-4.

220. Bertomeu-Motos, A.; Ezquerro, S.; Barios, J.A.; Lledó, L.D.; Domingo, S.; Nann, M.; Martin, S.; Soekadar, S.R.; Garcia-Aracil, N. User activity recognition system to improve the performance of environmental control interfaces: A pilot study with patients. $J$. Neuroeng. Rehabil. 2019, 16, 1-9. [CrossRef] [PubMed]

221. Gaxiola-Tirado, J.A.; Iáñez, E.; Ortíz, M.; Gutiérrez, D.; Azorín, J.M. Effects of an exoskeleton-assisted gait motor imagery training in functional brain connectivity. In Proceedings of the 2019 41st Annual International Conference of the IEEE Engineering in Medicine and Biology Society (EMBC), Berlin, Germany, 23-27 July 2019; pp. 429-432.

222. Vourvopoulos, A.; Pardo, O.M.; Lefebvre, S.; Neureither, M.; Saldana, D.; Jahng, E.; Liew, S.L. Effects of a brain-computer interface with virtual reality (VR) neurofeedback: A pilot study in chronic stroke patients. Front. Hum. Neurosci. 2019, 13, 210. [CrossRef]

223. Vourvopoulos, A.; Jorge, C.; Abreu, R.; Figueiredo, P.; Fernandes, J.C.; Bermúdez i Badia, S. Efficacy and brain imaging correlates of an immersive motor imagery BCI-driven VR system for upper limb motor rehabilitation: A clinical case report. Front. Hum. Neurosci. 2019, 13, 244. [CrossRef] [PubMed]

224. Badesa, F.J.; Diez, J.A.; Barios, J.A.; Catalan, J.M.; Garcia-Aracil, N. Evaluation of performance and heart rate variability during intensive usage of a BCI-controlled hand exoskeleton. In Proceedings of the 2020 8th IEEE RAS/EMBS International Conference for Biomedical Robotics and Biomechatronics (BioRob), New York, NY, USA, 29 November-1 December 2020; pp. 164-169.

225. Rodríguez-Ugarte, M.; Iáñez, E.; Ortiz, M.; Azorín, J.M. Improving real-time lower limb motor imagery detection using tDCS and an exoskeleton. Front. Neurosci. 2018, 12, 757. [CrossRef]

226. Quiles, E.; Suay, F.; Candela, G.; Chio, N.; Jiménez, M.; Álvarez-Kurogi, L. Low-Cost Robotic Guide Based on a Motor Imagery Brain-Computer Interface for Arm Assisted Rehabilitation. Int. J. Environ. Res. Public Health 2020, 17, 699. [CrossRef]

227. Rodríguez-Ugarte, M.; Iáñez, E.; Ortíz, M.; Azorín, J.M. Personalized offline and pseudo-online BCI models to detect pedaling intent. Front. Neuroinformatics 2017, 11, 45. [CrossRef] [PubMed]

228. Peterson, V.; Galván, C.; Hernández, H.; Spies, R. A feasibility study of a complete low-cost consumer-grade brain-computer interface system. Heliyon 2020, 6, e03425. [CrossRef] [PubMed]

229. Romero-Laiseca, M.A.; Delisle-Rodriguez, D.; Cardoso, V.; Gurve, D.; Loterio, F.; Nascimento, J.H.P.; Krishnan, S.; Frizera-Neto, A.; Bastos-Filho, T. A low-cost lower-limb brain-machine interface triggered by pedaling motor imagery for post-stroke patients rehabilitation. IEEE Trans. Neural Syst. Rehabil. Eng. 2020, 28, 988-996. [CrossRef]

230. Anil, D.G.; Pelayo, P.; Mistry, K.S.; George, K. A tactile P300 based brain computer interface system for communication in iOS devices. In Proceedings of the 2018 IEEE International Instrumentation and Measurement Technology Conference (I2MTC), Houston, TX, USA, 14-17 May 2018; pp. 1-6.

231. Casey, A.; Azhar, H.; Grzes, M.; Sakel, M. BCI controlled robotic arm as assistance to the rehabilitation of neurologically disabled patients. Disabil. Rehabil. Assist. Technol. 2019, 1-13. [CrossRef]

232. Wang, K.J.; Zhang, L.; Luan, B.; Tung, H.W.; Liu, Q.; Wei, J.; Sun, M.; Mao, Z.H. Brain-computer interface combining eye saccade two-electrode EEG signals and voice cues to improve the maneuverability of wheelchair. In Proceedings of the 2017 International Conference on Rehabilitation Robotics (ICORR), London, UK, 17-20 July 2017; pp. 1073-1078.

233. Samson, V.; Kitti, B.P.; Kumar, S.P.; Babu, D.S.; Monica, C. Electroencephalogram-based OpenBCI devices for disabled people. In Proceedings of the 2nd International Conference on Micro-Electronics, Electromagnetics and Telecommunications; Springer: Berlin/Heidelberg, Germany, 2018; pp. 229-238.

234. Chiu, M.; Murthy, H.; George, K. Mobile switch control using auditory and haptic steady state response in Ear-EEG. In Proceedings of the 2018 9th IEEE Annual Ubiquitous Computing, Electronics \& Mobile Communication Conference (UEMCON), New York, NY, USA, 8-10 November 2018; pp. 1032-1037. 
235. Perera, C.J.; Naotunna, I.; Sadaruwan, C.; Gopura, R.A.R.C.; Lalitharatne, T.D. SSVEP based BMI for a meal assistance robot. In Proceedings of the 2016 IEEE International Conference on Systems, Man, and Cybernetics (SMC), Budapest, Hungary, 9-12 October 2016; pp. 002295-002300.

236. Long, X.; Ma, Y.; Ma, X.; Yan, Z.; Wang, C.; Wu, X. The EEG-based lower limb exoskeleton system optimization strategy based on channel selection. In Proceedings of the 2019 IEEE International Conference on Real-time Computing and Robotics (RCAR), Irkutsk, Russia, 4-9 August 2019; pp. 1-6.

237. Long, X.; Liu, D.X.; Liang, S.; Yan, Z.; Wu, X. An eeg-based bci system for controlling lower exoskeleton to step over obstacles in realistic walking situation. In Proceedings of the 2018 15th International Conference on Control, Automation, Robotics and Vision (ICARCV), Singapore, 18-21 November 2018; pp. 1609-1614.

238. Duan, S.; Wang, C.; Li, M.; Long, X.; Wu, X.; Feng, W. Haptic and visual enhance-based motor imagery BCI for rehabilitation lower-limb exoskeleton. In Proceedings of the 2019 IEEE International Conference on Robotics and Biomimetics (ROBIO), Dali, China, 6-8 December 2019; pp. 2025-2030.

239. Wang, Z.; Wang, C.; Lv, Q.; Wu, G.; Zhang, T.; Wu, X. Implementation of brain-computer interface based on SSVEP for control of a lower-limb exoskeleton. In Proceedings of the 2016 IEEE International Conference on Information and Automation (ICIA), Ningbo, China, 1-3 August 2016; pp. 1882-1886.

240. Rimbert, S.; Bougrain, L.; Fleck, S. Learning how to generate kinesthetic motor imagery using a BCI-based learning environment: A comparative study based on guided or trial-and-error approaches. In Proceedings of the 2020 IEEE International Conference on Systems, Man, and Cybernetics (SMC), Toronto, ON, Canada, 11-14 October 2020; pp. 2483-2498.

241. Yazmir, B.; Reiner, M. Monitoring brain potentials to guide neurorehabilitation of tracking impairments. In Proceedings of the 2017 International Conference on Rehabilitation Robotics (ICORR), London, UK, 17-20 July 2017; pp. $983-988$.

242. Liu, X.; Liang, S.; Hang, W.; Lei, B.; Wang, Q.; Qin, J.; Choi, K.S. Performance evaluation of walking imagery training based on virtual environment in brain-computer interfaces. In Proceedings of the 2017 IEEE International Symposium on Multimedia (ISM), Taichung, Taiwan, 11-13 December 2017; pp. 25-30.

243. Ganin, I.; Kosichenko, E.; Sokolov, A.; Ioannisyanc, O.; Arefev, I.; Basova, A.Y.; Kaplan, A.Y. Adapting the p300 brain-computer interface technology to assess condition of anorexia nervosa patients. Bull. Russ. State Med. Univ. 2019. [CrossRef]

244. Frolov, A.A.; Mokienko, O.; Lyukmanov, R.; Biryukova, E.; Kotov, S.; Turbina, L.; Nadareyshvily, G.; Bushkova, Y. Post-stroke rehabilitation training with a motor-imagery-based brain-computer interface (BCI)-controlled hand exoskeleton: A randomized controlled multicenter trial. Front. Neurosci. 2017, 11, 400. [CrossRef]

245. Gordleeva, S.Y.; Lobov, S.A.; Grigorev, N.A.; Savosenkov, A.O.; Shamshin, M.O.; Lukoyanov, M.V.; Khoruzhko, M.A.; Kazantsev, V.B. Real-time EEG-EMG human-machine interface-based control system for a lower-limb exoskeleton. IEEE Access 2020, 8, 84070-84081. [CrossRef]

246. Kotov, S.; Turbina, L.; Bobrov, P.; Frolov, A.; Pavlova, O.; Kurganskaya, M.; Biryukova, E. Rehabilitation of stroke patients with a bioengineered "brain-computer interface with exoskeleton" system. Neurosci. Behav. Physiol. 2016, 46, 518-522. [CrossRef]

247. Kiselev, A.R.; Maksimenko, V.A.; Shukovskiy, N.; Pisarchik, A.N.; Pitsik, E.; Hramov, A.E. Post-stroke rehabilitation with the help of brain-computer interface. In Proceedings of the 2019 3rd School on Dynamics of Complex Networks and Their Application in Intellectual Robotics (DCNAIR), Innopolis, Russia, 9-11 September 2019; pp. 83-85.

248. Grubov, V.; Kiselev, A.; Badarin, A.; Schukovsky, N. Braincomputer interface for post-stroke rehabilitation. Cybern. Phys. 2019, 8, 251-256. [CrossRef]

249. Zhuralvev, M.; Runnova, A.; Kiselev, A. Characteristics of post-stroke patients brain activity with real and imagined movements in the BCI-rehabilitation process. Procedia Comput. Sci. 2020, 169, 677-685. [CrossRef]

250. Latif, M.Y.; Naeem, L.; Hafeez, T.; Raheel, A.; Saeed, S.M.U.; Awais, M.; Alnowami, M.; Anwar, S.M. Brain computer interface based robotic arm control. In Proceedings of the 2017 International Smart Cities Conference (ISC2), Wuxi, China, 14-17 September 2017; pp. 1-5.

251. Ndulue, C.; Orji, R. Driving Persuasive Games with Personal EEG Devices: Strengths and Weaknesses. In Proceedings of the Adjunct Publication of the 27th Conference on User Modeling, Adaptation and Personalization, Larnaca, Cyprus, 9-12 June 201 pp. 173-177.

252. Meza, A.; Baltazar, R.; Casillas, M.; Zamudio, V.; Mosiño, F.; Serna, B. System Development for Automatic Control Using BCI. In Agents and Multi-agent Systems: Technologies and Applications 2019; Springer: Berlin/Heidelberg, Germany, 2020 ; pp. 175-184.

253. Chowdhury, M.A.S.; Saha, D.K. Processing of motor imagery EEG Signals for controlling the opening and the closing of artificial hand. In Proceedings of the 2019 4th International Conference on Electrical Information and Communication Technology (EICT), Khulna, Bangladesh, 20-22 December 2019; pp. 1-5.

254. Quiroz, G.; Valdez, A.E.; Ruiz, R.S.; Mercado, L. Coherence analysis of EEG in locomotion using graphs. Mex. J. Biomed. Eng. 2017, 38, 235-246.

255. Murakami, M.; Nakatani, S.; Araki, N.; Konishi, Y.; Mabuchi, K. Motion discrimination from EEG using logistic regression and Schmitt-trigger-type threshold. In Proceedings of the 2015 IEEE International Conference on Systems, Man, and Cybernetics, Hong Kong, China, 9-12 October 2015; pp. 2338-2342.

256. Mishchenko, Y.; Kaya, M.; Ozbay, E.; Yanar, H. Developing a three-to six-state EEG-based brain-computer interface for a virtual robotic manipulator control. IEEE Trans. Biomed. Eng. 2018, 66, 977-987. [CrossRef] [PubMed] 
257. Kuhner, D.; Fiederer, L.D.J.; Aldinger, J.; Burget, F.; Völker, M.; Schirrmeister, R.T.; Do, C.; Boedecker, J.; Nebel, B.; Ball, T.; et al. A service assistant combining autonomous robotics, flexible goal formulation, and deep-learning-based brain-computer interfacing. Robot. Auton. Syst. 2019, 116, 98-113. [CrossRef]

258. Bastos-Filho, T.; Romero, M.; Cardoso, V.; Pomer, A.; Longo, B.; Delisle, D. A setup for lower-limb post-stroke rehabilitation based on motor imagery and motorized pedal. In Latin American Conference on Biomedical Engineering; Springer: Berlin/Heidelberg, Germany, 2019; pp. 1125-1129.

259. McCrimmon, C.M.; Wang, M.; Lopes, L.S.; Wang, P.T.; Karimi-Bidhendi, A.; Liu, C.Y.; Heydari, P.; Nenadic, Z.; Do, A.H. A small, portable, battery-powered brain-computer interface system for motor rehabilitation. In Proceedings of the 2016 38th Annual International Conference of the IEEE Engineering in Medicine and Biology Society (EMBC), Orlando, FL, USA, 16-20 August 2016; pp. 2776-2779.

260. Lee, S.H.; Kim, S.S.; Lee, B.H. Action observation training and brain-computer interface controlled functional electrical stimulation enhance upper extremity performance and cortical activation in patients with stroke: A randomized controlled trial. Physiother. Theory Pract. 2020, 1-9. [CrossRef]

261. Melinscak, F.; Montesano, L.; Minguez, J. Asynchronous detection of kinesthetic attention during mobilization of lower limbs using EEG measurements. J. Neural Eng. 2016, 13, 016018. [CrossRef]

262. Mokienko, O.; Lyukmanov, R.K.; Chernikova, L.; Suponeva, N.; Piradov, M.; Frolov, A. Brain-computer interface: The first experience of clinical use in Russia. Hum. Physiol. 2016, 42, 24-31. [CrossRef]

263. Lisi, G.; Hamaya, M.; Noda, T.; Morimoto, J. Dry-wireless EEG and asynchronous adaptive feature extraction towards a plug-and-play co-adaptive brain robot interface. In Proceedings of the 2016 IEEE International Conference on Robotics and Automation (ICRA), Stockholm, Sweden, 16-21 May 2016; pp. 959-966.

264. Qin, Z.; Xu, Y.; Shu, X.; Hua, L.; Sheng, X.; Zhu, X. eConhand: A wearable brain-computer interface system for stroke rehabilitation. In Proceedings of the 2019 9th International IEEE/EMBS Conference on Neural Engineering (NER), San Francisco, CA, USA, 20-23 March 2019; pp. 734-737.

265. Mrachacz-Kersting, N.; Jiang, N.; Stevenson, A.J.T.; Niazi, I.K.; Kostic, V.; Pavlovic, A.; Radovanovic, S.; Djuric-Jovicic, M.; Agosta, F.; Dremstrup, K.; et al. Efficient neuroplasticity induction in chronic stroke patients by an associative brain-computer interface. J. Neurophysiol. 2016, 115, 1410-1421. [CrossRef] [PubMed]

266. Jia, T.; Li, C.; Guan, X.; Ji, L. Enhancing engagement during robot-assisted rehabilitation integrated with motor imagery task. In Proceedings of the 2019 International Conference on Intelligent Medicine and Health, Ningbo, China, 1-3 July 201 ; pp. 12-16.

267. Lim, H.; Ku, J. Flickering exercise video produces mirror neuron system (MNS) activation and steady state visually evoked potentials (SSVEPs). Biomed. Eng. Lett. 2017, 7, 281-286. [CrossRef] [PubMed]

268. Chai, R.; Naik, G.R.; Ling, S.H.; Nguyen, H.T. Hybrid brain-computer interface for biomedical cyber-physical system application using wireless embedded EEG systems. Biomed. Eng. Online 2017, 16, 1-23. [CrossRef] [PubMed]

269. Kaur, M.; Singh, B. Implementation of SSVEP technology to develop assistive devices. In Progress in Advanced Computing and Intelligent Engineering; Springer: Berlin/Heidelberg, Germany, 2018; pp. 687-699.

270. Lu, R.R.; Zheng, M.X.; Li, J.; Gao, T.H.; Hua, X.Y.; Liu, G.; Huang, S.H.; Xu, J.G.; Wu, Y. Motor imagery based brain-computer interface control of continuous passive motion for wrist extension recovery in chronic stroke patients. Neurosci. Lett. 2020, 718, 134727. [CrossRef]

271. Norman, S.L.; Dennison, M.; Wolbrecht, E.; Cramer, S.C.; Srinivasan, R.; Reinkensmeyer, D.J. Movement anticipation and EEG: Implications for BCI-contingent robot therapy. IEEE Trans. Neural Syst. Rehabil. Eng. 2016, 24, 911-919. [CrossRef]

272. Ferreira, A.L.S.; de Miranda, L.C.; de Miranda, E.E.C.; Sakamoto, S.G. A survey of interactive systems based on brain-computer interfaces. SBC J. Interact. Syst. 2013, 4, 3-13. [CrossRef]

273. Soufineyestani, M.; Dowling, D.; Khan, A. Electroencephalography (EEG) Technology Applications and Available Devices. Appl. Sci. 2020, 10, 7453. [CrossRef]

274. Li, M.; Liu, Y.; Wu, Y.; Liu, S.; Jia, J.; Zhang, L. Neurophysiological substrates of stroke patients with motor imagery-based brain-computer interface training. Int. J. Neurosci. 2014, 124, 403-415. [CrossRef] [PubMed]

275. Villa-Parra, A.; Delisle-Rodríguez, D.; López-Delis, A.; Bastos-Filho, T.; Sagaró, R.; Frizera-Neto, A. Towards a robotic knee exoskeleton control based on human motion intention through EEG and sEMGsignals. Procedia Manuf. 2015, 3, 1379-1386. [CrossRef]

276. Belkacem, A.N. Cybersecurity framework for P300-based brain computer interface. In Proceedings of the 2020 IEEE International Conference on Systems, Man, and Cybernetics (SMC), Toronto, ON, Canada, 11-14 October 2020; pp. 1-6.

277. Lepa, S.; Steffens, J.; Herzog, M.; Egermann, H. Popular Music as Entertainment Communication: How Perceived Semantic Expression Explains Liking Previously Unknown Music. Media Commun. 2020. [CrossRef]

278. van de Laar, B.; Gürkök, H.; Bos, D.P.O.; Poel, M.; Nijholt, A. Experiencing BCI control in a popular computer game. IEEE Trans. Comput. Intell. AI Games 2013, 5, 176-184. [CrossRef]

279. Ratti, E.; Waninger, S.; Berka, C.; Ruffini, G.; Verma, A. Comparison of medical and consumer wireless EEG systems for use in clinical trials. Front. Hum. Neurosci. 2017, 11, 398. [CrossRef]

280. Ramadan, R.A.; Vasilakos, A.V. Brain computer interface: Control signals review. Neurocomputing 2017, 223, 26-44. [CrossRef]

281. Kasim, M.A.A.; Low, C.Y.; Ayub, M.A.; Zakaria, N.A.C.; Salleh, M.H.M.; Johar, K.; Hamli, H. User-friendly labview gui for prosthetic hand control using emotiv eeg headset. Procedia Comput. Sci. 2017, 105, 276-281. [CrossRef] 
282. Li, K.; Sankar, R.; Arbel, Y.; Donchin, E. P300 based single trial independent component analysis on EEG signal. In International Conference on Foundations of Augmented Cognition; Springer: Berlin/Heidelberg, Germany, 2009; pp. 404-410.

283. Mihajlović, V.; Grundlehner, B.; Vullers, R.; Penders, J. Wearable, wireless EEG solutions in daily life applications: What are we missing? IEEE J. Biomed. Health Inform. 2014, 19, 6-21. [CrossRef] [PubMed] 